Alma Mater Studiorum - Università di Bologna DEPARTMENT OF ECONOMICS

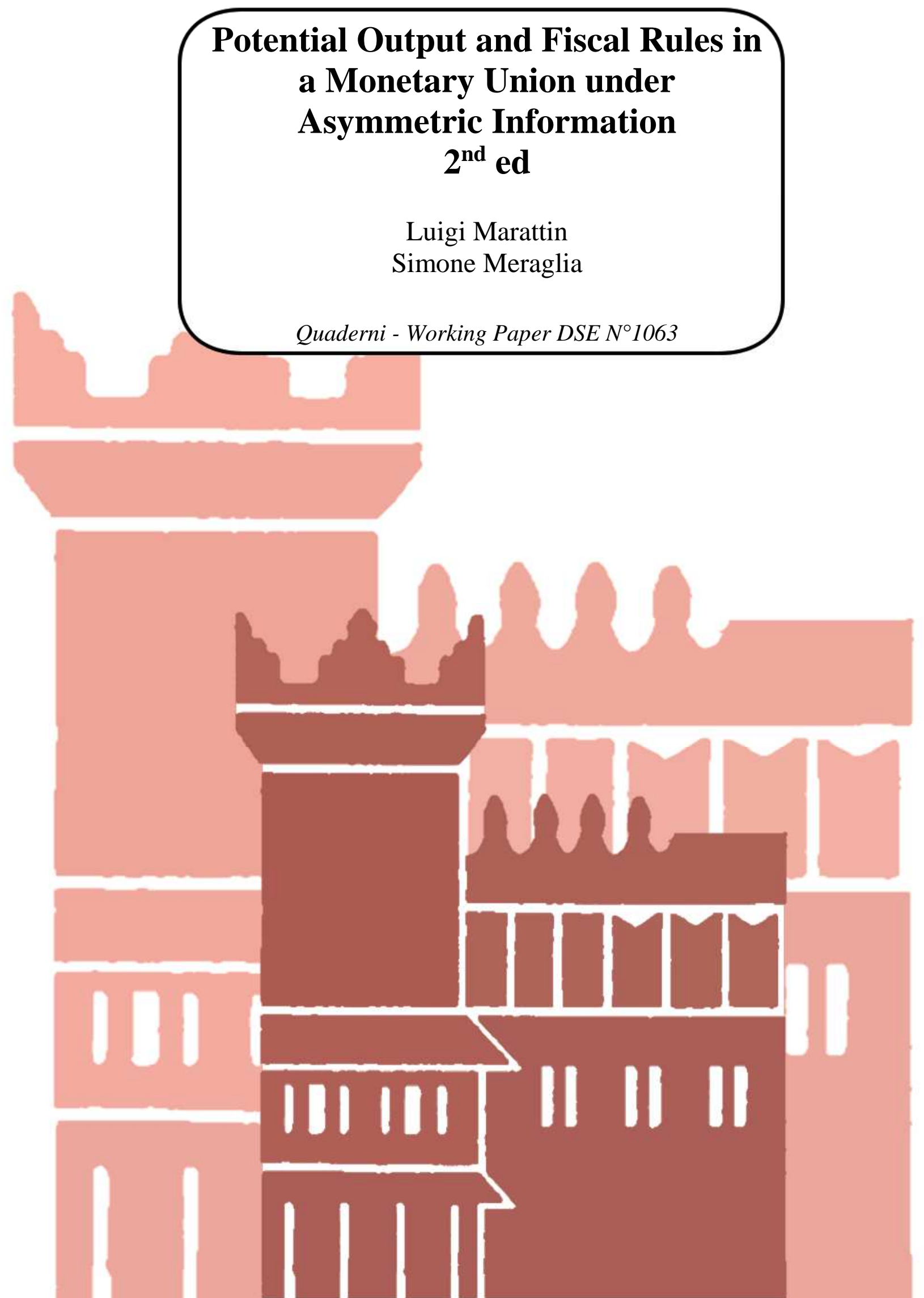




\title{
Potential Output and Fiscal Rules in a Monetary Union under
}

\author{
Asymmetric Information $-2^{\text {nd }}$ ed $^{*}$ \\ Luigi Marattin† Simone Meraglia ${ }^{\ddagger}$
}

April 19, 2016

\begin{abstract}
We analyze fiscal rules within a Monetary Union in the presence of (i) asymmetric information on member states' potential output and (ii) bail-out among member states. The first-best deficit is contingent on the cycle, that is, on member states' output gap. In the presence of asymmetric information and bailout, the first-best deficit is not implementable. Bail-out lowers the scope for signalling (discrimination) by member states (lenders) and induces overborrowing by member states characterized by a low output gap. The Monetary Union can design a mechanism such that a member state with a smaller negative output gap runs an optimal budget deficit upon receiving a transfer form the Union. We show that, this 'cyclically-contingent' fiscal framework Pareto dominates the 'cyclically-adjusted' fiscal rule currently enforced by the European Monetary Union. Our model can then account for a situation where both asymmetric information over cyclical positions and the presence of bail-out among member states does not induce borrowing distortions.
\end{abstract}

Keywords: Monetary Union, Potential Output, Output Gap, Asymmetric Information, Bail-Out, Fiscal Rules.

JEL Classification Numbers: E62, D82, F33, F34.

\footnotetext{
*A previous version of this paper was circulating as 'Marattin, Luigi and Simone Meraglia (2015), Bologna: Dipartimento di Scienze economiche DSE, p. 24. DOI 10.6092/unibo/amsacta/4312, in Quaderni - Working Paper DSE (1018), ISSN 2282-6483'. For helpful comments, we are grateful to Jan Auerbach, Alberto Bisin, Massimo Bordignon, Giacomo Calzolari, Paolo Manasse, Raoul Minetti, and Salvatore Nisticò. We also thank seminar participants at the University of Bologna, University of Exeter and the ESM (European Stability Mechanism) in Luxembourg; participants at the 3rd Macro, Banking and Finance Workshop in Pavia, the Financial Economics Workshop at NYU (2015), the PET Conference in Luxembourg (2015), the XXVII SIEP Conference in Ferrara (2015) and the EPCS Annual Meeting in Freiburg (2016). Usual disclaimers apply.

${ }^{\dagger}$ Department of Economics, University of Bologna. Email: luigi.marattin@unibo.it

${ }^{\ddagger}$ Department of Economics, University of Exeter. Email: s.meraglia@exeter.ac.uk
} 


\section{Introduction}

At the beginning of the European Monetary Union (EMU) institutional building process, fiscal rules on budget deficits were anchored solely to nominal constraints. Maastricht Treaty (1992) defined the so-called '3\%-rule', according to which member states must keep each year a ratio between nominal deficit and GDP not higher than 3\%. One of the main rationale for imposing a cap on member states' deficit is represented by the possibility - perceived by financial markets - that less 'virtuous' member states benefit from more 'virtuous' members' financial help (bail-out) and, therefore, fail to internalize the negative externality they impose on other Union's members and on monetary commitment (see, for instance Chari and Kehoe ]1998], Dixit and Lambertini [2001], Dixit [2001]). ${ }^{1}$

As a consequence of the 2010-2012 sovereign debt crisis, the 'Fiscal Compact' Treaty (2013) has modified the set of fiscal constraints in the EMU by adding a new rule based on a 'cyclically-adjusted' deficit target. The first questioning of cyclically-adjusted budget deficit as the most appropriate fiscal policy indicator dates back to Blanchard (1990). More recently, issues with the performance of cyclically-adjusted fiscal rules as compared to those based on nominal targets have been raised by many scholars (Debrun et al. [2008], Larch and Turrini [2009], Petrova [2012], Carnot [2014], Corders et al. [2015], Kinda [2015], Andrle et al. [2015]). At the EMU level, in the June 2015 Economic Bulletin, the European Central Bank acknolwedges that the fiscal adjustment path dictated by the new cyclically-adjusted set of rules is performing poorly (European Central Bank [2015]).

The main reason why the effectiveness of cyclically-adjusted fiscal rules might be questioned is that it ultimately relies on the computation of each country's potential output, from which - given the actual observable output level - it follows the size of the output gap. ${ }^{2}$ However, pinning down countries' potential output is very hard, and gives rise to many controversies between the European Commission and member states' governments. For instance, in April 2015, seven EMU governments officially asked the EU Commission for a revision of the potential output estimation procedures, stressing that the output gap'estimation by several international institutions (OECD, IMF) significantly differs from the EMU one.

In this paper, we argue that the cyclically-adjusted fiscal rules currently adopted in the EMU are suboptimal in the presence of intra-Union bail-out and asymmetric information over the member states' true potential output. When (i) national governments know their potential output better than the monetary union decision-making body does and (ii) the government spending multiplier increases with the magnitude

\footnotetext{
${ }^{1}$ The debate fiscal rules' optimal specification has always been lively and is based upon the difference in term of stabilization properties between deficit-based rules (Artis and Buti [2000], Brunila [2002], Buti et al. [2002], and Wyplosz [2002]) and expenditure-based rules (Bruck and Zwiener [2006]).

${ }^{2}$ A country's potential output is defined as the highest real output level - compatible with a stable inflation rate - that the country can sustain in the long-run.
} 
of the (negative) output gap, bail-out among member states makes them (a) less eager to signal their true cyclical position to the financial market and (b) more eager to inefficiently over-borrow on the financial market. ${ }^{3}$ The monetary union can prevent an excessive level of over-borrowing by posing a (pooling) constraint on each member state's borrowing level based on its own estimates of the member state's potential output. Alternatively, the monetary union can design a (separating) mechanism in which member states with smaller (negative) output gap self-select into the efficient level of borrowing upon receiving (ex-post) a lump-sum transfer from the Union. We show that, as the prior probability that a member state is characterized by a high potential output increases, the efficiency gains make the separating mechanism we build Pareto dominant with respect to the pooling cyclically-adjusted fiscal rules.

Our framework is based on two main premises. First, national governments have better information than Union-level decision-making bodies about their country's fiscal and cyclical stance. Second, the size of the government spending multiplier increases in the (negative) output gap.

Concerning our first premise, the presence of an asymmetric information problem between government layers has been deeply analyzed in the public finance literature. Locwkwood (1999), Bordignon et al (2001), Cornes and Silva (2002), Besfamille (2003), and Oates (2005) - among many others - argue that local governments have a superior knowledge of macroeconomic conditions and/or structural parameters of the economy. Bottazzi and Manasse (2005) explicitly bring the analysis to a monetary union level. They build a model where the true state of national business cycle is private information, and derive implications for the optimal (common) monetary policy. Our contribution follows this line. We assume that member states are better informed about their potential output with respect to the Monetary Union decision-making body. ${ }^{4}$ In particular, we study the interaction between this type of information asymmetry and bail-out among states members of a monetary union, and derive implications for the optimal fiscal policy.

Concerning our second premise, it is supported by solid contributions on both the theoretical and the empirical sides. From the theoretical viewpoint, Christiano et al. [2009] and Woodford [2010] note that the spending multiplier is higher during recessions because the economy is most likely to reach the zero lower bound on the nominal interest rate. ${ }^{5}$ In particular, the proportionality between slack capacity and output effects of the government spending stimulus comes from the fact that, because of the higher output gap, the government-spending-induced increase in output translates into a lower rise in inflation due to the flatter marginal cost curve which prevails under a great deal of excess capacity. This makes it easier for central

\footnotetext{
${ }^{3}$ Analyses on bail-out at the international level can be found in Corsetti et al (2006), and Bolton and Jeanne (2011).

${ }^{4}$ For instance, member states' potential output may be thought of as a function of the national government's past (structural) investments, where the efficiency of past investments - e.g., the fraction of investments that is not spent in socially wasteful private perks - is national government's private information.

${ }^{5}$ See also Manasse [2007].
} 
banks to maintain a constant real interest rate even in face of an aggregate demand stimulus. This intuition is empirically confirmed and fairly robust to alternative estimation techniques. Auerbach and Gorodnichenko [2012a] employ a regime-switching structural VAR (SVAR) with smooth transition across states, where the threshold variable is exogenously determined. ${ }^{6}$ The authors estimate a quarterly data model (1947-2009) for the US and find that the output effect of government spending is considerably larger during a recession rather than during an expansion. Auerbach and Gorodnichenko [2012b] and Batini et al. [2012] obtain similar results by looking at a larger sample of OECD countries. Baum et al. [2012] adopt a non-linear threshold VAR and - more importantly for our purposes - use output gap (rather than GDP growth) to define the cycle and better identify business fluctuations (see also Harding and Pagan [2002]). They investigate six of the G7 economies from the 1970s to 2011 and find that in all cases the magnitude of the multiplier size is increasing with the negative output gap.

The remainder of this paper proceeds as follows. Section 2 illustrates the current set of fiscal rules in the European Monetary Union and briefly discusses costs and benefits of targeting cyclically-adjusted variables. Section 3 lays out the model. We first solve the model under complete information and no bail-out (Section 3.1). We then insert both features and characterize the equilibrium in the decentralized setting (Section 3.2). Section 3.3. analyzes the optimal properties of two alternative fiscal rules - i.e., a pooling and a separating equilibrium - along with a Pareto ranking of all the equilibria. Section 4 briefly compares our model to the European Monetary Union current fiscal framework. Section 5 concludes and offers some policy implications.

\section{The Policy Background: the EMU Fiscal Framework}

The current European Monetary Union $(E M U)$ fiscal framework is defined by the Stability and Growth Pact (SGP), by the Treaty on Stability Coordination and Governance (TSCG) - better known as 'Fiscal Compact' - and by secondary legislation which defines the implementation process. ${ }^{7}$ This framework imposes a number of constraints on member states' fiscal policy aggregates: budget deficit (both nominal and cyclically-adjusted), public debt, and government spending. At the beginning of each year $t$, member states must submit Stability Programmes (SP) reporting the budgetary framework from year $t-1$ up to year $t+3$, so that the compliance with the whole above-described set of constraints can be assessed by EU authorities. Macroeconomic and budgetary forecasts are made at the national level - either by the government or by independent bodies - but must be compared with the forecasts performed by the EU Commission, which

\footnotetext{
${ }^{6}$ More specifically, Auerbach and Gorodnichenko [2012a] use a moving average representation of the GDP growth rate.

${ }^{7}$ SGP has been formulated in 1997 (art.121 of the Treaty on the Functioning of the European Union), implemented in 1999, and modified in 2005 and 2011. TSCG has been signed in 2012 by all EU Member States except Czech Republic and the United Kingdom. Concerning the secondary legislation, see Regulation 1175/2011 and Regulation 1177/2011.
} 
ultimately prevail in case of divergences. Here we focus only on the cyclically-adjusted flow constraint: each country is required to converge at the Medium Term Objective (MTO), identified as a structural budget deficit - in cyclically-adjusted $(C A)$ terms - net of one-off and other temporary measures. More specifically, it is defined as: ${ }^{8}$

$$
D_{t}^{C A}=D_{t}+\varepsilon^{D Y} \underbrace{\left(Y_{t}-Y_{t}^{*}\right)}_{\text {output gap }},
$$

where $D_{t}$ denotes nominal budget deficit, $Y_{t}$ denotes nominal output, $Y_{t}^{*}$ represents potential output, and $\varepsilon^{D Y}$ is the semi-elasticity of the budget deficit (as a ratio to aggregate output) to the business cycle. The semielasticity $\varepsilon^{D Y}$ measures the automatic non-discretionary change in nominal deficit-to-GDP ratio in response to output gap movements. From (1), $D_{t}^{C A}$ crucially depends on $\varepsilon^{D Y}$ and $Y_{t}^{*}$. Although pinning down $\varepsilon^{D Y}$ is not without potential ambiguity (see Mourre et al. [2013]), we focus on the estimation of $Y_{t}^{*} \cdot{ }^{9}$ In 2002 , the EU Council has established that the reference method for the estimation of member states' potential output is the 'production function approach'. This method computes potential output on the basis of a standard technology-augmented Cobb-Douglas production function with constant returns to scale on potential capital and labour (Denis et al. [2002], Roeger [2006]). Technology is estimated through a bivariate Kalman Filter that exploits the link between its cyclical component and the degree of capacity utilization measured using the Capacity Utilization Indicator (for the manufacturing sector) and the Business Survey Capacity Indicator (for the manufacturing sector, the construction sector, and services). Potential capital stock, measured by the perpetual inventory method, corresponds to its actual value, under the assumption of full utilization of the existing stock. The capital is extrapolated in the out-of-sample period according to a given profile of productive investment (estimated through an $\mathrm{AR}(2)$ process) and assuming a constant depreciation rate (Cacciotti et al. [2014]). Potential labour is calculated by a Kalman filter estimation of country-specific NAWRU, where the trend component is a random walk with drift, and the cyclical component is given by a Phillips Curve which relates the change in wage inflation to the unemployment rate and other exogenous variables (e.g., terms of trade and wage share). Particularly for the estimation of potential labour, the choice of some parameters (bounds of the shocks to trend, cycle and Phillips curve's slope) is crucial in determining the NAWRU and therefore the potential output (see Italy's Stability Programme, pp. 18-24).

Since 2015, the EU fiscal framework also makes the convergence speed towards the MTO dependent on cyclical conditions (i.e., magnitude and sign of the output gap) and debt-to-GDP ratio (EU Commis-

\footnotetext{
${ }^{8}$ Examples of temporary measures are sales of non-financial assets, receipts of auctions of public owned licenses, tax amnesties, etc..

${ }_{9} \varepsilon^{D Y}$ is computed as the weighted difference between the elasticities of, respectively, revenue-to-GDP and expenditure-toGDP to output, where the weights are given by the ten-years moving averages of output shares of revenue and expenditure.
} 
sion [2015]), thus further strengthening the countercyclical nature of fiscal rules. Through this important modification, the EU Commission further highlights the importance of countries' cyclical positions for the convergence towards the MTO and the achievements of the fiscal target.

The evaluation of the effectiveness of cyclically-adjusted fiscal rules presents both benefits and risks. On one hand, provided that they are able to correctly pin down the true potential output level, they are more suited to identify countries' true fiscal stance, irrespective of business cycle fluctuations. They also force member states to pursue optimal countercyclical fiscal policies, while providing them with a safety margin (up to the $3 \%$ limit) to expand the budget in response to negative output fluctuations, and viceversa (Siu [2004], Andres and Domenech [2006], Manasse [2007]). On the other hand, the main problem with cyclically-adjusted rules is that they require rigorous calculation and estimation of latent variables that are unobservable both ex-ante and ex-post. Particularly, the estimation of potential labour and TFP is extremely sensitive to parameters'selection, and the complexity of the procedure does not promote full transparency and accountability. Also the estimation of potential capital stock is troublesome, as it is derived as the sum of past investments that, in turn, are the most cyclical component of aggregate demand (see Cottarelli [2015]). Hence the final estimation might reflect past demand conditions rather than the structural supply features of an economy. Marcellino and Musso [2011] and Tereanu et al. [2014] document that mistakes in fiscal policy prescriptions due to the unreliability of potential output estimation can result in wrong fiscal adjustments, whose size is up to 1.5 per cent of GDP. Masten and Gnip [2016] compare the current EMU methodology to an alternative one derived from a DSGE estimation, and find that the former tend to over-estimate the role of discretionary fiscal policy. As a result, policy prescription turn out to be wrong.

As described in the introduction, in this paper we take the view that potential output is mainly determined by information on which national governments have a comparative advantage with respect to the monetary union decision-making body. Generally speaking, this assumption is supported by the fact that for instance - national governments know the 'effectiveness' of structural investments/reforms better than the EU. Particularly, given the method currently employed by EU institutions outlined in this section, we argue that crucial features of the output gap estimation and, thus, of the country's cyclical position (such as shocks to Kalman filter's latent components, which are necessary to initialize the filter and obtain the estimation of potential labour) are better known by member states. Equivalently, given the assumption that spending multipliers are increasing functions of capacity slack, the information asymmetry can be easily transferred to the multiplier's size. Both early reduced-form expressions (Keynes [1936]) and more recent ones based on deep structural parameters (Hall [2009], Woodford [2012]) highlight that the ex-ante output effect of government spending is determined by parameters on which is easy to assume the existence of an information 
advantage in favour of the member state. Given this information asymmetry, national governments have an incentive to over-estimate their output gap to be allowed a higher nominal deficit (see equation (1)). In our view, together with the presence of bail-out, this is the source of the problem generated by cyclically-adjusted fiscal rules within a monetary union.

\section{The Model}

Consider two countries $S_{i}$, for $i=1,2$, belonging to a monetary union $(M U)$ acting through an independent decision-making body. Each country finances public expenditures by recurring to both taxes and competitive outside investors. For the sake of simplicity, we normalize taxes to zero. ${ }^{10}$ Hence, in our simplified framework, public expenditures correspond to (primary) deficit $D_{i} \in[0,+\infty)$, for $i=1,2$. As we intend to mimic a short-run macroeconomic framework, we assume that deficit spending $D_{i}$ has real effects, i.e., it has a positive effect on income level $Y_{i}$ because of, for instance, nominal rigidities. We abstract from any disaggregation of $D_{i}$ into different public spending categories that might entail alternative multipler effects.

Each member state $S_{i}$ produces a stochastic end-of-period output $Y_{i}\left(\theta_{i}, D_{i}, \mu_{i}\right)$, where $\mu_{i}$ is a random variable, and where $\theta_{i} \in\{\underline{\theta}, \bar{\theta}\}$ represents $S_{i}$ 's cyclical position with respect to its potential output, with $\bar{\theta}>\underline{\theta}$, for $i=1,2$. More specifically, when $\theta_{i}=\bar{\theta}\left(\theta_{i}=\underline{\theta}\right)$, the absolute value of $S_{i}$ 's 'output gap' is large (small): given some initial condition on the output produced before the beginning of the (accounting) period, a large (small) output gap implies a large (small) 'potential output'. $S_{i}$ knows its type $\theta_{i}$ - i.e., it knows its current cyclical position as compared to its potential output - but $M U$ does not. $M U$ attaches probability $\alpha_{i}$ to $\theta_{i}=\bar{\theta}$, and $\left(1-\alpha_{i}\right)$ to $\theta_{i}=\underline{\theta}$, for $i=1,2$. Because we are only interested in short-run macroeconomic stabilization, we assume that potential output is exogenous and unaffected by $D_{i}$.

Given $\left(\theta_{i}, D_{i}\right)$, the random variable $\mu_{i}$ generates a probability density function $f_{i}\left(Y_{i} \mid \theta_{i}, D_{i}\right)$ and a distribution function $F_{i}\left(Y_{i} \mid \theta_{i}, D_{i}\right)$ for $Y_{i}$, for $i=1,2$. We closely follow Innes [1991], and assume $f_{i}(\cdot)$ is continuosly differentiable on $\left[d_{i}\left(\theta_{i}\right), K\left(\theta_{i}, D_{i}\right)\right]$, for $i=1,2$, where $K(\cdot)>d_{i}(\cdot)$ whenever $D_{i}>0$, for $i=1,2$. Also, following our discussion in Section 1 , we assume that a higher output gap $\theta$ and a higher deficit $D$ generate better output distributions in the sense of first-order stochastic dominance. More specifically, by removing the subscript $i$ for simplicity, we have:

$$
F_{\theta}(Y)<0, \quad F_{D}(Y)<0, \text { and } F_{D \theta}(Y)<0
$$

$\forall Y \in[0, K(d, D)]$, were subscripts denote partial derivatives. The last inequality in (2) implies that a larger output gap is associated with a higher multiplier of government spending. ${ }^{11}$ We finally assume that the

\footnotetext{
${ }^{10}$ Our normalization implies that $S_{i}$ invests all the collected taxes, for $i=1,2$.
}

${ }^{11}$ As argued at the end of Section 2 , this allows our model to be based equivalently either on the asymmetry about potential 
expected output $E\left[Y_{i} \mid \theta_{i}, D_{i}\right]$ is increasing and concave in $D_{i}$, and the Inada conditions hold, for $i=1,2 .{ }^{12}$

Financial Market and Bail-out. $S_{i}$, for $i=1,2$, signs a debt contract with perfectly competitive and risk neutral lenders. The contract consists of the amount $D_{i}$ borrowed by $S_{i}$ and a return $R_{i}\left(Y_{i}\right)=z_{i}$ for lenders to be paid at the end of the period. We take the return on a risk-free bond to be equal to zero. Like $M U$, lenders attach probability $\alpha_{i}$ to $\theta_{i}=\bar{\theta}$, and $\left(1-\alpha_{i}\right)$ to $\theta_{i}=\underline{\theta}$, for $i=1,2$.

In case $Y_{i}<z_{i}$, lenders receive:

$$
R_{i}\left(Y_{i}, x_{i j}\right)=\min \left\{Y_{i}+x_{i j}, z_{i}\right\}
$$

where $x_{i j} \geq 0$ denotes the amount of debt $D_{i}$ repaid to $S_{i}$ 's creditors by $S_{j}$, for $i, j=1,2$ and $i \neq j$ : this construction captures bail-out among states which are members of a monetary union. The presence of free-rider problems in a monetary union - in which member state borrow in a common currency - has been widely discussed in the literature (Buiter et al. [1993], Beetsma and Uhlig [1999], von Hagen and Eichengreen [1996], Lane [2012]). The attempt to overcome it by inserting an explicit 'no-bail-out clause' in the Maastricth Treaty (art. 125 of the Lisbon Treaty) has proved pretty much ineffective, as sovereign debt crisis in the Eurozone displayed its effects.

Utility Functions. $S_{i}$ 's utility function is:

$$
U_{i}\left(\theta_{i}, D_{i}\right)=t_{i}\left(\theta_{i}\right)+\int_{z_{i}}^{K\left(\theta_{i}, D_{i}\right)}\left[\left(Y_{i}-z_{i}\right) f_{i}\left(Y_{i} \mid \theta_{i}, D_{i}\right)\right] d Y_{i}-\int_{d_{j}\left(\theta_{j}\right)}^{z_{j}} \min \left[\left(z_{j}-Y_{j}\right), x_{j i}\right] f_{j}\left(Y_{j} \mid \theta_{j}, D_{j}\right) d Y_{j},
$$

for $\theta_{i} \in\{\underline{\theta}, \bar{\theta}\}$, where $t_{i}\left(\theta_{i}\right) \in \mathbb{R}$ represents an ex-post type-contingent transfer from $M U$ - and, therefore, $S_{j}-$ to $S_{i}$, for $i, j=1,2$ and $i \neq j .{ }^{13}$ The second term in the right-hand-side (RHS) in (4) is the (expected) cost to $S_{i}$ of bailing $S_{j}$ out. We assume debt repayment to lenders is senior with respect to transfers to $M U$. However, transfers received from $M U$ cannot be used to repay lenders. ${ }^{14}$

$M U$ 's utility function is:

$$
V=\sum_{i=1}^{2} \alpha_{i} U_{i}\left(\underline{\theta}, D_{i}\right)+\left(1-\alpha_{i}\right) U_{i}\left(\bar{\theta}, D_{i}\right) .
$$

output level or the size of government spending multiplier.

${ }^{12}$ As we disregard long-run considerations, the marginal utility of income is always increasing, so that national governments are not satiated with the closing of output gap because of political short-termism (see, for instance, Dixit and Lambertini [2001] and Ferrè [2008]).

${ }^{13}$ In particular, while $D_{i}$ is borrowed on the financial market at the beginning of the period, the transfer $t_{i}$ is cleared at the end of the period, i.e., after the realization of $Y_{i}$ is observed by all the players, for $i=1,2$.

${ }^{14}$ Given the simplifying assumptions we state below, imposing that transfers from $M U$ cannot be used to repay lenders does not affect our analysis. 
where the transfers $\left\{t_{1}, t_{2}\right\}$ cancel out in $M U$ 's utility.

Simplifying Assumption. In the following, we simplify our framework by shutting down both asymmetric information and bail-out for $S_{1}$ so as to focus on their joint effect on $S_{2}$ and $M U$. We assume $d_{1} \geq D_{1}^{*}+\bar{x}$, for $\theta_{1} \in\{\underline{\theta}, \bar{\theta}\}$, and for $D_{1}^{*}$ to be defined below (A1). We further take $f_{1}\left(Y_{1} \mid \theta_{1}, D_{1}\right)$ to be independent of $\theta_{1}$ (A2). A1 and A2 will allow us to focus on the case in which (i) asymmetric information about $S_{1}$ 's cyclical position plays no role and (ii) $S_{1}$ does not default on its debt contract and can possibly bail $S_{2}$ out by at least a fixed amount $\bar{x}$. We also assume that lenders expect $\bar{x}$ to be the maximum amount of $S_{2}$ 's debt repaid by $S_{1}$ (A3). Finally, we impose (A4):

$$
0=d_{2}(\underline{\theta})<D_{2}^{*}(\bar{\theta}) \leq d_{2}(\bar{\theta})
$$

for $D_{2}^{*}(\bar{\theta})$ to be defined below.

Given A1-A3, our focus is on the effect of asymmetric information and bail-out (by $S_{1}$ ) on $S_{2}$ 's government spending and $M U$ 's optimal policies. A4 further simplifies our framework by making bail-out relevant for $\theta_{2}=\underline{\theta}$ only (i.e., it ensures that the $\bar{\theta}$-type does not default on its debt when $D_{2} \leq D_{2}^{*}(\bar{\theta})$ ). Finally, notice that A1-A3 imply that $S_{2}$ 's default does not have any (contagion) effect on $S_{1}$

Timing. We analyze a one-period dynamic game. At the beginning of the period, Nature draws $\theta_{i}$, and this is perfectly revealed to $S_{i}$, for $i=1,2$. $M U$ sets a type contingent mechanism $\left\{t_{2}\left(\theta_{2}\right), D\left(\theta_{2}\right)\right\}$, for $\theta_{2} \in\{\underline{\theta}, \bar{\theta}\}$. Given $\left\{t_{2}\left(\theta_{2}\right), D\left(\theta_{2}\right)\right\}, S_{i}$ announces an investment level $D_{i}$, and competitive investors decide whether to lend $D_{i}$ subject to a repayment $z_{i}$, for $i=1,2$. Finally, $Y_{i}$ realizes, borrowers repay lenders, and transfers $t_{i}$ are made by $M U$, for $i=1,2$. Our solution concept is Perfect Bayesian Equilibrium $(P B E)$.

In what follows, we first characterize the optimal solution - which will serve as benchmark - without either asymmetric information or bail-out (Section 3.1). We then insert both the above features and characterize a 'decentralized' equilibrium (Section 3.2). We finally derive the equilibrium under a (i) 'separating' mechanism and (ii) 'pooling' rule (Section 3.3), and present a Pareto ranking of all the equilibria. When deriving the optimal pooling constraint on borrowing, we will assume that $M U$ can fully restrict $S_{i}$ 's choice of $D_{i}$ to the proposed mechanism.

\subsection{The Benchmark: Symmetric Information absent Bail-out.}

Suppose $\theta_{2}$ is perfectly observable by all the parties and bail-out is not allowed (i.e., $x_{12}=0$ ). Because lenders are competitive, we expect $S_{2}$ to appropriate the entire surplus generated by government spending. 
More specifically, $S_{2}$ solves:

$$
\begin{array}{r}
\max _{\left\{D_{2}\right\}} E\left[Y_{2} \mid \theta_{2}, D_{2}\right]-E\left[R_{2}\left(Y_{2}\right) \mid \theta_{2}, D_{2}\right], \\
\text { s.t. } E\left[R_{2}\left(Y_{2}\right) \mid D_{2}, \theta_{2}\right]=D_{2},
\end{array}
$$

where the constraint represents the zero-profit condition for lenders, and where we assume that the objective function is quasiconcave in $D_{2}$. From (7), $S_{2}$ solves:

$$
\max _{\left\{D_{2}\right\}} \int_{0}^{K\left(\theta_{2}, D_{2}\right)} Y_{2} f_{2}\left(Y_{2} \mid \theta_{2}, D_{2}\right) d Y_{2}-D_{2}
$$

which gives us the symmetric information optimal borrowing $D_{2}^{*}\left(\theta_{2}\right)$, for $\theta_{2} \in\{\underline{\theta}, \bar{\theta}\}$. From $(2)$, because $F_{D \theta}(Y)<$ 0 , we have $D_{2}^{*}(\bar{\theta})>D_{2}^{*}(\underline{\theta})$. That is, absent any information asymmetry or bail-out mechanism, optimality requires the high-potential output type to borrow more than the low-potential output type because - given our assumptions - it can exploit a higher spending multiplier.

\subsection{Asymmetric Information and Bail-out}

The investment pair $\left\{D_{2}^{*}(\bar{\theta}), D_{2}^{*}(\underline{\theta})\right\}$ also represents the efficient level of investment that maximizes $M U$ 's utility. However, due to both (i) asymmetric information over $\theta_{2}$ and (ii) bail-out by $S_{1}$ of $S_{2}$, the efficient investment may not be achieved in a decentralized setting.

To show our result, we first need to define (a) $S_{2}$ 's indifference curves and (b) lenders' offer curves. Let us set $t_{2}\left(\theta_{2}\right)=0$ and, from $\mathbf{A} 1, x_{21}=0$. $S_{2}$ 's indifference curve $I C\left(\theta_{2}\right)$ is the set of points on the $\left(D_{2}, z_{2}\right)$ space that yield a common utility level to $S_{2}$.

$$
U_{2}\left(\theta_{2}, D_{2}, z_{2}\right)=\int_{z_{2}}^{K\left(\theta_{2}, D_{2}\right)}\left(Y_{2}-z_{2}\right) f_{2}\left(Y_{2} \mid \theta_{2}, D_{2}\right) d Y_{2}=\bar{U}\left(\theta_{2}\right) \text {, }
$$

for $\theta_{2} \in\{\underline{\theta}, \bar{\theta}\}$. A lender's offer curve is the set of points on the $\left(D_{2}, z_{2}\right)$ space that yield an expected profit equal to zero. As in Innes [1991], it useful to distinguish the separating offer curves from the pooling one. For expositional purposes, we first define the offer curves for the case in which bail-out is absent, and we then discuss how they are modified with the inclusion of of bail-out. The separating offer curve $O C\left(\theta_{2}\right)$ is: 


$$
R_{2}\left(\theta_{2}, D_{2}, z_{2}\right)=E\left[Y_{2} \mid \theta_{2}, D_{2}\right]-\left[\int_{z_{2}}^{K\left(\theta_{2}, D_{2}\right)}\left(Y_{2}-z_{2}\right) f_{2}\left(Y_{2} \mid \theta_{2}, D_{2}\right) d Y_{2}\right]-D_{2}=0
$$

for $\theta_{2} \in\{\underline{\theta}, \bar{\theta}\}$. The pooling offer curve $O C^{P}$ is:

$$
\alpha_{2} R_{2}\left(\bar{\theta}, D_{2}, z_{2}\right)+\left(1-\alpha_{2}\right) R_{2}\left(\underline{\theta}, D_{2}, z_{2}\right)=0 .
$$

Unlike Innes [1991], the separating and the pooling offer curves are affected by bail-out $\left(x_{12}\right)$.

In the following, we assume (A5):

$$
\bar{x} \geq\left(d_{2}(\bar{\theta})-d_{2}(\underline{\theta})\right) .
$$

The potential bail-out from $S_{1}(\bar{x})$ is sufficiently high to make $\underline{\theta}$-type identical to $\bar{\theta}$-type, i.e., both types have a zero probability of default for sufficiently low values of $D_{2}$ (see $\mathbf{A 4}$ ).

In our model, bail-out affects the loan payment $z_{2}$ (from (3)). Hence, in the presence of bail-out, the offer curve in (10) is independent of $\theta_{2}$, and is equal to (11).

We follow Innes [1991], and we impose that when $S_{2}$ is characterized by a large output gap ( $\bar{\theta}$-type) it has steeper indifference curves than when facing a small output gap ( $\underline{\theta}$-type):

$$
\left.\frac{d z_{2}}{d D_{2}}\right|_{\bar{U}(\bar{\theta})}=-\frac{\frac{\partial U_{2}(\bar{\theta}, \cdot)}{\partial D_{2}}}{\frac{\partial U_{2}(\bar{\theta}, \cdot)}{\partial z_{2}}}>-\frac{\frac{\partial U_{2}(\underline{\theta}, \cdot)}{\partial D_{2}}}{\frac{\partial U_{2}(\underline{\theta}, \cdot)}{\partial z_{2}}}=\left.\frac{d z_{2}}{d D_{2}}\right|_{\bar{U}(\underline{\theta})},
$$

where the indifference curve is upward sloping because:

$$
\begin{gathered}
\frac{\partial U_{2}\left(\theta_{2}, \cdot\right)}{\partial D_{2}}=-\int_{z_{2}}^{K\left(\theta_{2}, D_{2}\right)} \frac{\partial F_{2}\left(Y_{2} \mid \theta_{2}, D_{2}\right)}{\partial D_{2}} d Y_{2}>0, \\
\frac{\partial U_{2}\left(\theta_{2}, \cdot\right)}{\partial z_{2}}=-\left(1-F\left(z_{2} \mid \theta_{2}, D_{2}\right)\right)<0,
\end{gathered}
$$

for $\theta_{2} \in\{\underline{\theta}, \bar{\theta}\}$. Finally, the lenders' offer curves are upward sloping:

$$
\left.\frac{d z_{2}}{d D_{2}}\right|_{R_{2}\left(\theta_{2}\right)=0} \geq 1, \quad \text { for } \theta_{2} \in\{\underline{\theta}, \bar{\theta}\}
$$

where, absent bail-out, the slope of the offer curve is decreasing in $\theta_{2}$. As we pointed out above, given A4-A5, in the presence of bail-out the offer curve in (10) is independent of $\theta_{2}$ (and lies on the $45^{\circ}$ line, for $\left.D_{2} \leq d_{2}(\bar{\theta})\right)$.

Figure 1 illustrates the pair of contracts that arise in (i) a symmetric information setting without bail-out and (ii) an asymmetric information setting in the presence of bail-out. The offer curves $O C^{P}$ and $O C\left(\theta_{2}\right)$, 
Figure 1: Equilibria under (i) Complete Information and (ii) Asymmetric Information and Bail-out.

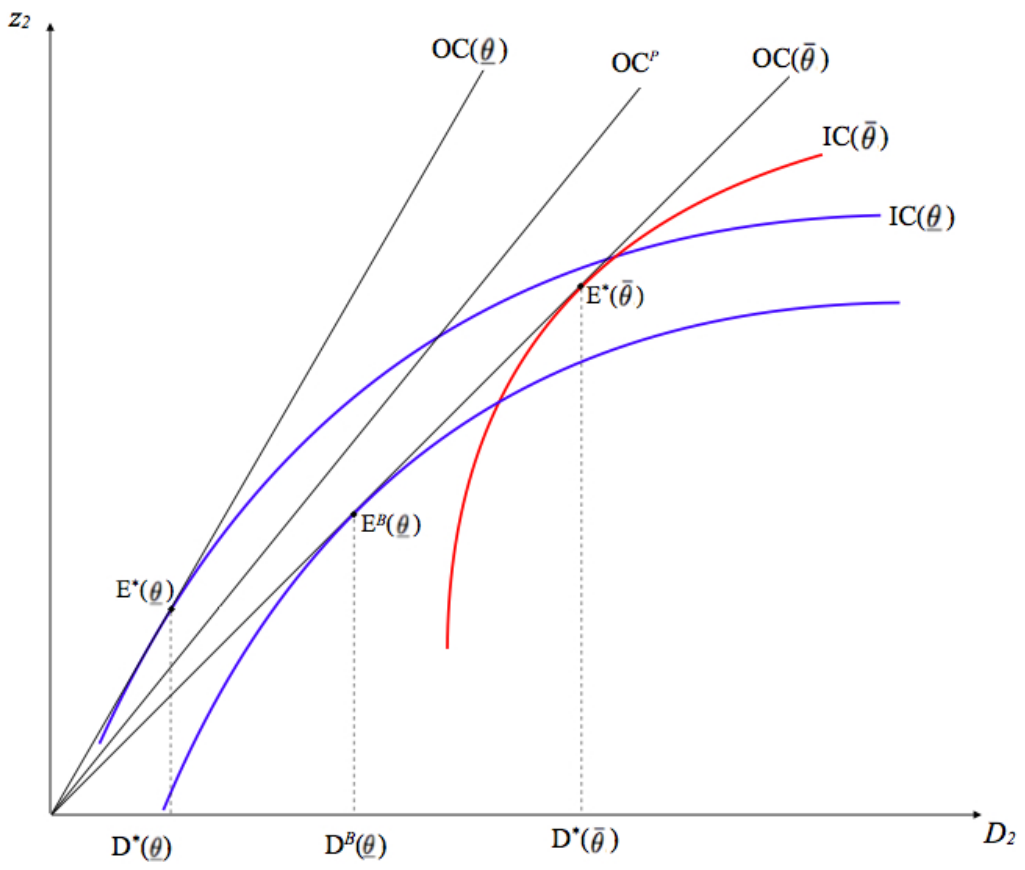

for $\theta_{2} \in\{\underline{\theta}, \bar{\theta}\}$, are depicted for the case in which bail-out is absent. In the presence of bail-out, there is a unique offer curve given by $O C(\bar{\theta})$. Indifference curves are also depicted (in blue for the $\underline{\theta}$-type and in red for the $\bar{\theta}$-type); higher levels of utility correspond to indifference curves moving 'southward'. The 'complete information allocations' are represented by the pair $\left\{E^{*}(\underline{\theta}), E^{*}(\bar{\theta})\right\}$, where the indifference curves for each type are tangent to the corresponding offer curves.

Let us denote by a superscript $B$ (for bail-out) $S_{2}$ 's optimal borrowing in the presence of bail-out and asymmetric information.

Proposition 1. In the presence of bail-out and asymmetric information, $S_{2}$ does not signal its type to the financial market. The $\bar{\theta}$-type borrows optimally, i.e., $D_{2}(\bar{\theta})=D_{2}^{*}(\bar{\theta})$, while the $\underline{\theta}$-type over-borrows on the financial market, i.e., $D_{2}(\underline{\theta})=D_{2}^{B}(\underline{\theta})>D_{2}^{*}(\underline{\theta})$, where $D_{2}^{B}(\underline{\theta})<D_{2}^{*}(\bar{\theta})$.

Proof. First, given A4-A5, in the presence of bail-out both types of $S_{2}$ are identical and risk-free to lenders. Bail-out hence implies that the two separating offer curves in (10) are identical and equal to $O C(\bar{\theta})$, which 
in turn implies that the pooling offer curve in (11) is also identical to $O C(\bar{\theta})$. Hence, because there is no cross-subsidization between types, on the one hand the $\bar{\theta}$-type has no incentive to signal its type, and invests optimally $D_{2}(\bar{\theta})=D_{2}^{*}(\bar{\theta})$; on the other hand, because bail-out lowers the $\underline{\theta}$-type's probability of default, the $\underline{\theta}$-type sets:

$$
\begin{gathered}
D_{2}^{B}(\underline{\theta}, \bar{x})=\arg \max _{D_{2}} \int_{z_{2}}^{K(\cdot)}\left(Y_{2}-z_{2}\right) f_{2}\left(Y_{2} \mid \underline{\theta}, D_{2}\right) d Y_{2} \\
\text { s.t. } \quad \int_{0}^{\max \left\{z_{2}-\bar{x}, 0\right\}} Y_{2} f_{2}\left(Y_{2} \mid \underline{\theta}, D_{2}\right) d Y_{2}+\int_{\max \left\{z_{2}-\bar{x}, 0\right\}}^{K(\cdot)} z_{2} f_{2}\left(Y_{2} \mid \underline{\theta}, D_{2}\right) d Y_{2}=D_{2},
\end{gathered}
$$

where, given A1-A5, the constraint can be written as $z_{2}(\bar{x})=D_{2}$, as long as $D_{2}^{B}(\underline{\theta}, \bar{x})<D_{2}^{*}(\bar{\theta})$. Therefore:

$$
D_{2}^{B}(\underline{\theta}, \bar{x})=\arg \max _{D_{2}} \int_{D_{2}}^{K(\cdot)}\left(Y_{2}-D_{2}\right) f_{2}\left(Y_{2} \mid \theta_{2}, D_{2}\right) d Y_{2}
$$

Hence, because $z_{2}(\underline{\theta}, \bar{x})<z_{2}(\underline{\theta}, 0)$, we have $D_{2}^{B}(\underline{\theta}, \bar{x})>D_{2}^{*}(\underline{\theta})$. Also, $D_{2}^{B}(\underline{\theta}, \bar{x})<D_{2}^{*}(\bar{\theta})$ (from $F_{D \theta}<0$ in (2)), which finally confirms that $z_{2}(\bar{x})=D_{2}$.

The pair $\left\{E^{B}(\underline{\theta}), E^{*}(\bar{\theta})\right\}$ in Figure 1 represents the decentralized equilibrium - that is, the equilibrium absent $M U$ 's intervention - under asymmetric information and in the presence of bail-out. The inefficient over-investment by the $\underline{\theta}$-type is caused by the potential bail-out (perceived by lenders) among $M U$ 's member states. The member state with a lower potential output - and, therefore, a lower marginal productivity of government spending - tends to overborrow because it does not internalize the bail-out by $S_{1}$. At the same time, because potential bail-out is internalized by the financial market, neither lenders require any signalling by $S_{2}$, nor the member state with a higher potential output needs to signal its type by, for instance, overborrowing (see Innes [1991]). ${ }^{15} 16$ As a result, both sides of the debt contract do not have incentives to discriminate among types, and the member state with a low potential output issues debt in excess.

In order to analyze $S_{1}$ 's utility, let us denote its expected level of utility when $\left\{E^{B}(\underline{\theta}), E^{*}(\bar{\theta})\right\}$ emerges, as $U_{1}^{B}\left(\alpha_{2}\right)$.

Lemma 1. In the presence of bail-out and asymmetric information, $S_{1}$ 's expected utility in the decentralized equilibrium is increasing in $\alpha_{2}$.

\footnotetext{
${ }^{15}$ Compared to Innes [1991], Figure 1 depicts the case in which (absent bail-out) asymmetric information would call for the $\bar{\theta}$-type to over-invest - i.e., borrow some $D_{2}^{\prime}(\bar{\theta})>D_{2}^{*}(\bar{\theta})$ - to signal to lenders the higher value of its multiplier of government spending with respect to that of the $\underline{\theta}$-type.

${ }^{16}$ Our 'no-signalling' result hinges on bail-out from $S_{1}$ to make $\underline{\theta}$-type identical to $\bar{\theta}$-type (see A5). More generally, bail-out (at least) partially dilutes the difference between types of borrowers: hence, by reducing cross-subsidization, bail-out reduces the incentives for signalling.
} 
Proof. First, define $U_{1}^{*}=\max _{D_{1}} \int_{D_{1}}^{K(\cdot)} Y_{1} f_{1}\left(Y_{1} \mid D_{1}\right) d Y_{1}-D_{1}$, where we define as $D_{1}^{*}$ the value of $D_{1}$ that solves the optimization problem. We have:

$$
U_{1}^{B}\left(\alpha_{2}\right)=\alpha_{2} U_{1}^{*}+\left(1-\alpha_{2}\right)[U_{1}^{*}-\underbrace{\int_{0}^{z_{2}\left(\bar{x}, D_{2}^{B}\right)} \min \left[z_{2}\left(\bar{x}, D_{2}^{B}\right)-Y_{2}, \bar{x}\right] f_{2}\left(Y_{2} \mid \underline{\theta}, D_{2}^{B}\right) d Y_{2}}_{\text {Bail-out Component }}],
$$

where, from A1-A5 and Proposition 1, we have $z_{2}\left(\bar{x}, D_{2}^{B}\right)=D_{2}^{B}$ and $\min \left[D_{2}^{B}-Y_{2}, \bar{x}\right]=D_{2}^{B}-Y_{2}$. We can then rewrite (19):

$$
U_{1}^{B}\left(\alpha_{2}, \bar{x}\right)=U_{1}^{*}-\left(1-\alpha_{2}\right) \int_{0}^{D_{2}^{B}}\left(D_{2}^{B}-Y_{2}\right) f_{2}\left(Y_{2} \mid \underline{\theta}, D_{2}^{B}\right) d Y_{2},
$$

where the RHS is increasing in $\alpha_{2}$.

To sum up, in the presence of asymmetric information and bail-out, (i) member states do not have incentives to signal their types, nor the financial market requires them to do so, (ii) the low-potential output type inefficiently over-borrows on the market, as it is proteced by the bail-out umbrella, and (iii) a higher prior probability that $S_{2}$ has a high-potential induces a lower the expected cost of bail-out and, therefore, leads to a higher expected welfare for $S_{1}$.

We now investigate $M U$ 's possible interventions to re-establish an efficient level of borrowing at the Monetary Union level, along with their impact on all member states' level of expected utility.

\subsection{Fiscal Rules Under Asymmetric Information and Bail-out}

From $M U$ 's viewpoint, bail-out causes an inefficient over-borrowing by the $\underline{\theta}$-type of $S_{2}$. $M U$ 's objective is then to implement the efficient choices $\left(D_{2}^{*}(\underline{\theta}), D_{2}^{*}(\bar{\theta})\right)$ given the presence of bail-out and asymmetric information.

We first investigate the possibility for $M U$ to build a mechanism $\left\{\left(t_{2}(\underline{\theta}), D_{2}^{*}(\underline{\theta})\right),\left(t_{2}(\bar{\theta}), D_{2}^{*}(\bar{\theta})\right)\right\}$ to separate the two types of $S_{2} \cdot{ }^{17}$ We then solve our model for $M U$ 's optimal pooling equilibrium, i.e., for the equilibrium in which $M U$ sets a rule on $S_{2}$ 's borrowing independent of its type $\theta_{2}$. We finally study the conditions under which the separating mechanism we build is Pareto efficient from the Monetary Union viewpoint with respect to the pooling mechanism and the decentralized solution $\left(D_{2}^{B}(\underline{\theta}), D_{2}^{*}(\bar{\theta})\right)$.

\footnotetext{
${ }^{17}$ The revelation principle applies. Hence, we focus on direct revelation mechanisms.
} 


\subsubsection{MU's Separating Mechanism}

Let us define $t_{2}(\underline{\theta}) \equiv \underline{t}_{2}, t_{2}(\bar{\theta}) \equiv \bar{t}_{2}, D_{2}^{*}(\underline{\theta}) \equiv \underline{D}_{2}^{*}$, and $D_{2}^{*}(\bar{\theta}) \equiv \bar{D}_{2}^{*}$. The Incentive Compatibility Constraints $\left(I C C_{\theta_{2}}\right)$ are:

$$
\begin{gathered}
\underline{t}_{2}+\int_{z_{2}\left(\underline{L}_{2}^{*}, \bar{x}\right)}^{K\left(\underline{\theta}_{2}, \underline{D}_{2}^{*}\right)}\left(Y_{2}-z_{2}\left(\underline{D}_{2}^{*}, \bar{x}\right)\right) f_{2}\left(Y_{2} \mid \underline{\theta}, \underline{D}_{2}^{*}\right) d Y_{2} \geq \bar{t}_{2}+\int_{z_{2}\left(\bar{D}_{2}^{*}, \bar{x}\right)}^{K\left(\underline{\theta}, \bar{D}_{2}^{*}\right)}\left(Y_{2}-z_{2}\left(\bar{D}_{2}^{*}, \bar{x}\right)\right) f_{2}\left(Y_{2} \mid \underline{\theta}, \bar{D}_{2}^{*}\right) d Y_{2}, \\
\bar{t}_{2}+\int_{z_{2}\left(\bar{D}_{2}^{*}, \bar{x}\right)}^{K\left(\bar{\theta}, \bar{D}_{2}^{*}\right)}\left(Y_{2}-z_{2}\left(\bar{D}_{2}^{*}, \bar{x}\right)\right) f_{2}\left(Y_{2} \mid \bar{\theta}, \bar{D}_{2}^{*}\right) d Y_{2} \geq \underline{t}_{2}+\int_{z_{2}\left(\underline{D}_{2}^{*}, \bar{x}\right)}^{K\left(\bar{\theta}, \underline{D}_{2}^{*}\right)}\left(Y_{2}-z_{2}\left(\underline{D}_{2}^{*}, \bar{x}\right)\right) f_{2}\left(Y_{2} \mid \bar{\theta}, \underline{D}_{2}^{*}\right) d Y_{2},
\end{gathered}
$$

for $\theta_{2}=\underline{\theta}$ and $\theta_{2}=\bar{\theta}$ respectively, with $z_{2}\left(D_{2}^{*}\left(\theta_{2}\right), \bar{x}\right)=D_{2}^{*}\left(\theta_{2}\right)$ (from A1-A5), for $\theta_{2} \in\{\underline{\theta}, \bar{\theta}\}$.

When compared to the decentralized solution, the Participation Constraints $\left(P C_{\theta_{2}}\right.$, for $\left.\theta_{2} \in\{\underline{\theta}, \bar{\theta}\}\right)$ are:

$$
\begin{gathered}
\underline{t}_{2}+\int_{\underline{D}_{2}^{*}}^{K\left(\underline{\theta}, \underline{D}_{2}^{*}\right)}\left(Y_{2}-z_{2}\left(\underline{D}_{2}^{*}, \bar{x}\right)\right) f_{2}\left(Y_{2} \mid \underline{\theta}, \underline{D}_{2}^{*}\right) d Y_{2} \geq \int_{D_{2}^{B}}^{K\left(\underline{\theta}^{B}, D_{2}^{B}\right)}\left(Y_{2}-z_{2}\left(D_{2}^{B}, \bar{x}\right)\right) f_{2}\left(Y_{2} \mid \underline{\theta}, D_{2}^{B}\right) d Y_{2}, \\
\bar{t}_{2}+\int_{z_{2}\left(\bar{D}_{2}^{*}, \bar{x}\right)}^{K\left(\bar{\theta}, \bar{D}_{2}^{*}\right)}\left(Y_{2}-z_{2}\left(\bar{D}_{2}^{*}, \bar{x}\right)\right) f_{2}\left(Y_{2} \mid \bar{\theta}, \bar{D}_{2}^{*}\right) d Y_{2} \geq \int_{z_{2}\left(\bar{D}_{2}^{*}, \bar{x}\right)}^{K\left(\bar{\theta}, \bar{D}_{2}^{*}\right)}\left(Y_{2}-z_{2}\left(\bar{D}_{2}^{*}, \bar{x}\right)\right) f_{2}\left(Y_{2} \mid \bar{\theta}, \bar{D}_{2}^{*}\right) d Y_{2},
\end{gathered}
$$

for $\theta_{2}=\underline{\theta}$ and $\theta_{2}=\bar{\theta}$ respectively.

From (24), because the $\bar{\theta}$-type's borrowing choice is not distorted in the decentralized equilibrium, it is straightforward to show that $P C_{\bar{\theta}}$ holds $\forall \bar{t}_{2} \geq 0$. By contrast, from (23) and by construction of $D_{2}^{B}(\underline{\theta})$, we have that $\underline{t}_{2}>0$ for $P C_{\underline{\theta}}$ to hold.

Lemma 2. When compared to the decentralized borrowing level $\left(D_{2}^{B}(\underline{\theta}), D_{2}^{*}(\bar{\theta})\right), M U$ can implement efficient borrowing $\left(D_{2}^{*}(\underline{\theta}), D_{2}^{*}(\bar{\theta})\right)$ by setting:

$$
\begin{gathered}
\underline{t}_{2}^{*}=\int_{D_{2}^{B}(\underline{\underline{\theta})}}^{K\left(\underline{\underline{\theta}, D_{2}^{B}}\right)}\left(Y_{2}-D_{2}^{B}\right) f_{2}\left(Y_{2} \mid \underline{\theta}, D_{2}^{B}\right) d Y_{2}-\int_{\underline{D}_{2}^{*}}^{K\left(\underline{\theta}, \underline{\underline{D}}_{2}^{*}\right)}\left(Y_{2}-\underline{D}_{2}^{*}\right) f_{2}\left(Y_{2} \mid \underline{\theta}, \underline{D}_{2}^{*}\right) d Y_{2}>0 \\
\bar{t}_{2}^{*}=0 .
\end{gathered}
$$

Proof. First, it is easily verified that the pair $\left(\underline{t}_{2}^{*}, \vec{t}_{2}^{*}\right)$ verifies $P C_{\theta_{2}}$ as an equality, for $\theta_{2} \in\{\underline{\theta}, \bar{\theta}\}$. Second, substituting (25)-(26) in (21), it is easily shown that $I C C_{\underline{\theta}}$ also holds (as an equality). Finally, substituting (25)-(26) in (22), by definition of $D_{2}^{*}(\bar{\theta})$, we have that $I C C_{\bar{\theta}}$ holds as a strict inequality. 
Figure 2: Separating Mechanism in the Presence of Bail-out.

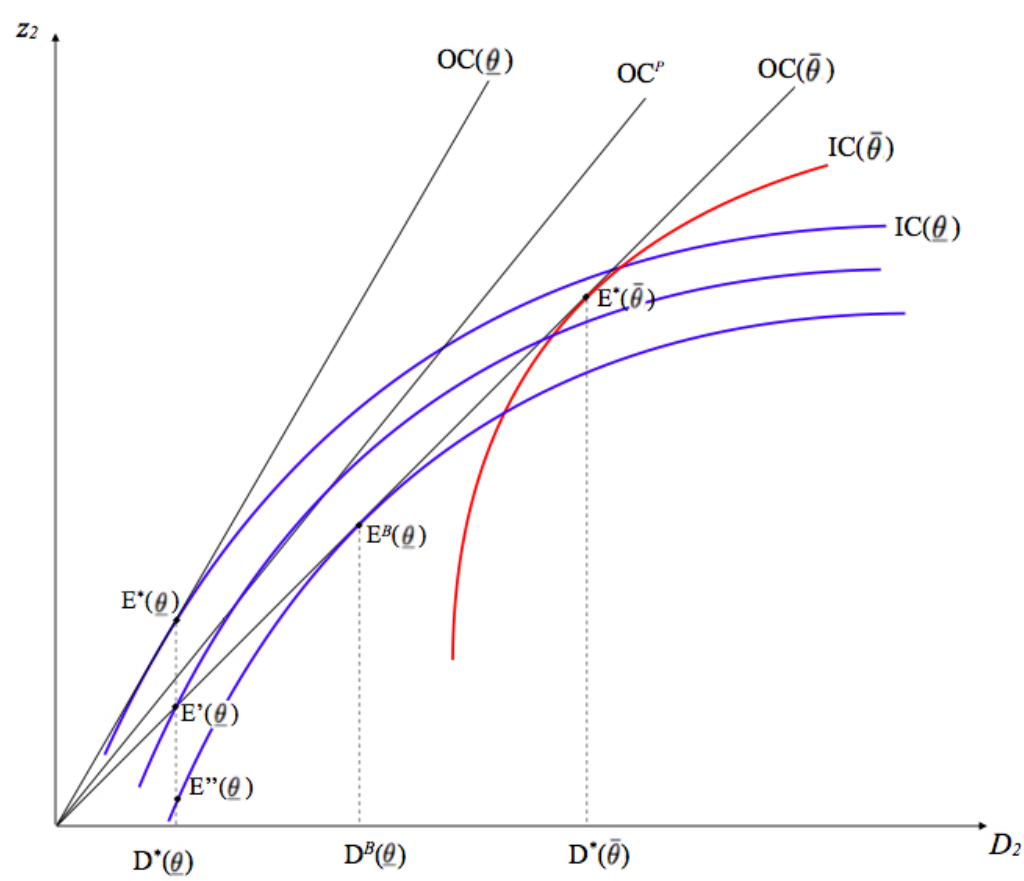

The separating equilibrium constructed by $M U$ - as defined in Lemma 2 - is denoted by the pair of points $\left\{E^{\prime \prime}(\underline{\theta}), E^{*}(\bar{\theta})\right\}$ in Figure 2 .

The $\underline{\theta}$-type of $S_{2}$ is made indifferent between its decentralized allocation (under asymmetric information and bail-out) and the mechanism proposed by $M U$. As in standard asymmetric information settings, an information rent arises: in order to induce the $\underline{\theta}$-type not to mimic the $\bar{\theta}$-type and over-borrow, $M U$ must promise it a lump-sum transfer $\underline{t}_{2}$ at least equal to its expected loss in utility. ${ }^{18}$ In Figure 2, the information rent implies that the $\underline{\theta}$-type allocation lies below the bail-out offer curve $O C(\bar{\theta})$.

\subsubsection{MU's Pooling Mechanism}

An alternative solution for $M U$ to the separating mechanism constructed above is represented by a pooling mechanism. More specifically, $M U$ can set a unique level $D_{2}^{P}$ to act as a constraint on $S_{2}$ 's borrowing independently of its type $\theta_{2}$. This is the solution $M U$ can resort to whenever it finds it too difficult - given the imperfect observability of potential output - to establish each country's cyclical position.

\footnotetext{
${ }^{18}$ Alternatively, $M U$ could have imposed a fine for over-borrowing (with respect to $\underline{D}_{2}^{*}$ ), still taking $I C C_{\underline{\theta}}$ into account. However, this would not make the separating mechanism a Pareto dominant outcome, as the $\bar{\theta}$-type would be negatively affected. Because the Pareto analysis is a main component of our paper, we focus on the allocation defined in Lemma 2.
} 
Figure 3: Pooling and Separating Solutions in the Presence of Bail-out.

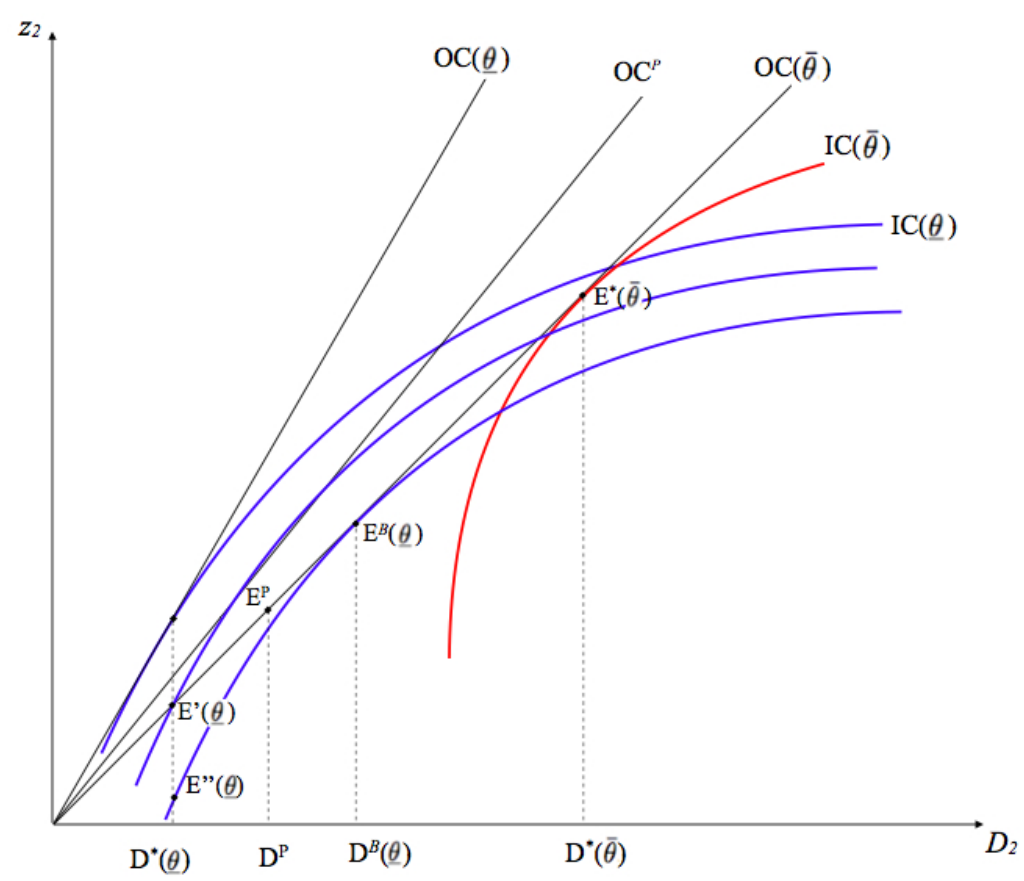

To determine the optimal pooling constraint, $M U$ solves:

$$
\begin{array}{cl} 
& \max _{\left.D_{1}, D_{2}\right\}} U_{1}\left(D_{1}, \bar{x}\right)+\alpha_{2} U_{2}\left(\underline{\theta}, D_{2}, \bar{x}\right)+\left(1-\alpha_{2}\right) U_{2}\left(\bar{\theta}, D_{2}, \bar{x}\right) \\
\text { s.t. } \quad & \alpha_{2} E\left\{R_{2}\left(Y_{2}, \bar{x} \mid \bar{\theta}, D_{2}\right)\right\}+\left(1-\alpha_{2}\right) E\left\{R_{2}\left(Y_{2}, \bar{x} \mid \underline{\theta}, D_{2}\right)\right\}=D_{2}, \\
& z_{1}=D_{1} .
\end{array}
$$

Given A1-A5, it is easily seen that $M U$ sets $D_{1}=D_{1}^{*}$. From (4), $M U$ 's optimal choice of $D_{2}$ is:

$$
\begin{gathered}
D_{2}^{P}\left(\alpha_{2}\right)=\arg \max _{D_{2}} \alpha_{2}\left\{\int_{D_{2}}^{K\left(\bar{\theta}, D_{2}\right)}\left(Y_{2}-D_{2}\right) f_{2}\left(Y_{2} \mid \bar{\theta}, D_{2}\right) d Y_{2}\right\}+ \\
+\left(1-\alpha_{2}\right)\left\{\int_{D_{2}}^{K\left(\underline{\theta}, D_{2}\right)}\left(Y_{2}-D_{2}\right) f_{2}\left(Y_{2} \mid \underline{\theta}, D_{2}\right) d Y_{2}-\int_{0}^{D_{2}}\left(D_{2}-Y_{2}\right) f_{2}\left(Y_{2} \mid \underline{\theta}, D_{2}\right) d Y_{2}\right\},
\end{gathered}
$$

where, $z_{2}=D_{2}$ because of bail-out. From (7), it is straightforward to show that the solution to MU's problem is given by:

$$
D_{2}^{P}\left(\alpha_{2}\right)=\alpha_{2} D_{2}^{*}(\bar{\theta})+\left(1-\alpha_{2}\right) D_{2}^{*}(\underline{\theta}) .
$$

The optimal pooling solution on borrowing is represented by the point $E^{P}$ in Figure 3. $E^{P}$ lays on $O C(\bar{\theta})$ 
- because of bail-out - between $E^{\prime}(\underline{\theta})$ and $E^{*}(\bar{\theta})$ : the higher $\alpha_{2}$ is, the closer is $E^{P}$ to $E^{*}(\bar{\theta})$.

\subsubsection{Pareto Analysis}

We are interested in conducting a Pareto analysis of the different mechanisms computed in the previous subsections. More specifically, we compare the following outcomes in terms of their welfare implications for all the players involved, i.e., $S_{1}$ and both types of $S_{2}$ :

1. $\left\{E^{B}(\underline{\theta}), E^{*}(\bar{\theta})\right\}$ : the outcome arising under asymmetric information and bail-out, and absent $M U$ 's intervention;

2. $\left\{E^{\prime \prime}(\underline{\theta}), E^{*}(\bar{\theta})\right\}$ : the outcome arising under asymmetric information and bail-out, when $M U$ implements a separating mechanism (see Lemma 2);

3. $E^{P}$ : the outcome arising under asymmetric information and bail-out, when $M U$ implements a pooling mechanism.

In the following, we interpret the levels of $D_{2}$ chosen by $M U$ as upperbounds on $S_{2}$ 's level of borrowing rather than as a fixed level of borrowing. It should be clear from our discussion that this interpretation can only improve welfare within the monetary union. ${ }^{19}$

We proceed by comparing first $\left\{E^{B}(\underline{\theta}), E^{*}(\bar{\theta})\right\}$ to $\left\{E^{\prime \prime}(\underline{\theta}), E^{*}(\bar{\theta})\right\}$.

Proposition 2. The separating mechanism $\left\{\left(\underline{t}_{2}^{*}, \underline{D}_{2}^{*}\right),\left(\vec{t}_{2}^{*}, \bar{D}_{2}^{*}\right)\right\}$ Pareto dominates the decentralized outcome in which the $\bar{\theta}$-type of $S_{2}$ invests $\bar{D}_{2}^{*}$, and the $\underline{\theta}$-type of $S_{2}$ invests $D_{2}^{B}(\underline{\theta})$.

Proof. First, by construction, the separating mechanism $\left(\underline{t}_{2}^{*}, \underline{D}_{2}^{*}\right),\left(\vec{t}_{2}^{*}, \bar{D}_{2}^{*}\right)$ Pareto dominates the decentralized solution for both types of $S_{2}$ (see Lemma 2).

Second, from (4) and (25), $S_{1}$ 's expected utility from the separating mechanism is:

$$
U_{1}^{S}\left(\alpha_{2}, \bar{x}\right)=U_{1}^{*}-\left(1-\alpha_{2}\right)\left\{\int_{D_{2}^{B}}^{K\left(\underline{\theta}, D_{2}^{B}\right)}\left(Y_{2}-D_{2}^{B}\right) f_{2}\left(Y_{2} \mid \underline{\theta}, D_{2}^{B}\right) d Y_{2}-\left[\int_{0}^{K\left(\underline{\theta}_{2}^{*}\right)} Y_{2} f_{2}\left(Y_{2} \mid \underline{\theta}, \underline{D}_{2}^{*}\right) d Y_{2}-\underline{D}_{2}^{*}\right]\right\},
$$

\footnotetext{
${ }^{19}$ See the proof of Proposition 3.
} 
and $S_{1}$ 's expected utility from the decentralized solution is given by (19), which we report for simplicity:

$$
U_{1}^{B}\left(\alpha_{2}, \bar{x}\right)=U_{1}^{*}-\left(1-\alpha_{2}\right) \int_{0}^{D_{2}^{B}}\left(D_{2}^{B}-Y_{2}\right) f_{2}\left(Y_{2} \mid \underline{\theta}, D_{2}^{B}\right) d Y_{2}
$$

Hence, from (30) and (19), $S_{1}$ has a higher utility under the separating mechanism rather than the decentralized solution if:

$$
\int_{0}^{K\left(\underline{\theta}, \underline{D}_{2}^{*}\right)} Y_{2} f_{2}\left(Y_{2} \mid \underline{\theta}, \underline{D}_{2}^{*}\right) d Y_{2}-\underline{D}_{2}^{*} \geq \int_{0}^{K\left(\underline{\theta}, D_{2}^{B}(\underline{\theta}, \bar{x})\right)} Y_{2} f_{2}\left(Y_{2} \mid \underline{\theta}, D_{2}^{B}(\underline{\theta}, \bar{x})\right) d Y_{2}-D_{2}^{B}(\underline{\theta}, \bar{x}),
$$

which holds by definition of $\underline{D}_{2}^{*}$.

In the presence of asymmetric information and bail-out, $S_{1}$ finds it profitable to compensate the $\underline{\theta}$-type of $S_{2}$ with a lump-sum amount of money to induce it to self-select on the efficient amount of borrowing. Because (i) total welfare within the Monetary Union increases and (ii) the separating mechanism is such that both types of $S_{2}$ are indifferent between the efficient level of borrowing and the decentralized solution, $S_{1}$ appropriates the efficiency gains created by this type-contingent mechanism. In other words, $S_{1}$ prefers to pay a certain lump-sum transfer rather than face the expected cost of a potential bail-out.

Even though the separating mechanism we propose Pareto dominates the decentralized solution - at the $M U$ level - it is important to understand whether the separating mechanism Pareto dominates the pooling mechanism.

Proposition 3. There exists a unique threshold $\alpha_{2}^{*}$ such that, for $\alpha_{2} \geq \alpha_{2}^{*}$, the separating mechanism $\left\{\left(\underline{t}_{2}^{*}, \underline{D}_{2}^{*}\right),\left(\vec{t}_{2}^{*}, \bar{D}_{2}^{*}\right)\right\}$ Pareto dominates the pooling rule $D_{2}^{P}\left(\alpha_{2}\right)$.

Proof. From (29), we have $D_{2}^{P}\left(\alpha_{2}\right) \in\left[\underline{D}_{2}^{*}, \bar{D}_{2}^{*}\right]$, where $D_{2}^{P}\left(\alpha_{2}\right)$ is increasing in $\alpha_{2}$. Hence, there exists a unique value $\tilde{\alpha}_{2}$ such that, for $\alpha_{2}=\tilde{\alpha}_{2}$, we have $D_{2}^{P}\left(\tilde{\alpha}_{2}\right)=D_{2}^{B}(\underline{\theta})$.

Consider first $\alpha_{2} \geq \tilde{\alpha}_{2}$. In this case, the pooling rule $D_{2}^{P}\left(\alpha_{2}\right)$ is Pareto dominated by the decentralized solution $\left(D_{2}^{B}(\underline{\theta}), D_{2}^{*}(\bar{\theta})\right)$. In fact (i) the $\underline{\theta}$-type of $S_{2}$ is indifferent between the decentralized solution and the pooling rule as $D_{2}^{P}\left(\alpha_{2}\right) \geq D_{2}^{B}(\underline{\theta})$ and it optimally borrows $D_{2}^{B}(\underline{\theta})$, (ii) the $\bar{\theta}$-type of $S_{2}$ is better-off - strictly better-off for $\alpha_{2}>\tilde{\alpha}_{2}$ - under the decentralized solution, because it can borrow at the efficient level, and (iii) $S_{1}$ is indifferent between the decentralized solution and the pooling rule, because the $\underline{\theta}$-type 
of $S_{2}$ borrows $D_{2}^{B}(\underline{\theta})$ in both cases and the $\bar{\theta}$-type is 'risk-free'. Hence, because the separating mecha$\operatorname{nism}\left\{\left(\underline{t}_{2}^{*}, \underline{D}_{2}^{*}\right),\left(\vec{t}_{2}^{*}, \bar{D}_{2}^{*}\right)\right\}$ Pareto dominates the decentralized solution (see Proposition 2), it also Pareto dominates the pooling rule $D_{2}^{P}\left(\alpha_{2}\right)$ for $\alpha_{2} \geq \tilde{\alpha}_{2}$.

Consider now $\alpha_{2}<\tilde{\alpha}_{2}$. In this case, from both types of $S_{2}$ obtain a higher utility under the separating mechanism rather than the pooling rule: by construction, under the separating mechanism, the $\underline{\theta}$-type obtains the payoff of the decentralized outcome, and the $\bar{\theta}$-type borrows efficiently and, therefore, obtains the highest possible payoff. Hence, to perform our Pareto analysis, we need to compare $S_{1}$ 's payoffs under the two rules. For easy of reference, we report $S_{1}$ 's payoff from the pooling rule $U_{1}^{P}\left(\alpha_{2}\right)$ and the separating mechanism $U_{1}^{S}\left(\alpha_{2}\right)$ :

$$
\begin{gathered}
U_{1}^{P}\left(\alpha_{2}\right)=U_{1}^{*}+\left(1-\alpha_{2}\right)\left[\int_{0}^{D_{2}^{P}\left(\alpha_{2}\right)}\left(D_{2}^{P}\left(\alpha_{2}\right)-Y_{2}\right) f_{2}\left(Y_{2} \mid \underline{\theta}, D_{2}^{P}\left(\alpha_{2}\right)\right) d Y_{2}\right], \\
U_{1}^{S}\left(\alpha_{2}\right)=U_{1}^{*}-\left(1-\alpha_{2}\right)\left\{\int_{D_{2}^{B}}^{K\left(\underline{\theta}, D_{2}^{B}\right)}\left(Y_{2}-D_{2}^{B}\right) f_{2}\left(Y_{2} \mid \underline{\theta}, D_{2}^{B}\right) d Y_{2}-\left[\int_{0}^{K\left(\underline{\theta}, \underline{D}_{2}^{*}\right)} Y_{2} f_{2}\left(Y_{2} \mid \underline{\theta}, \underline{D}_{2}^{*}\right) d Y_{2}-\underline{D}_{2}^{*}\right]\right\} .
\end{gathered}
$$

(32) can be rewritten as:

$U_{1}^{P}\left(\alpha_{2}\right)=U_{1}^{*}-\left(1-\alpha_{2}\right)\left\{\int_{D_{2}^{P}\left(\alpha_{2}\right)}^{K\left(\underline{\theta}, D_{2}^{P}\left(\alpha_{2}\right)\right)}\left(Y_{2}-D_{2}^{P}\left(\alpha_{2}\right)\right) f_{2}\left(Y_{2} \mid \underline{\theta}, D_{2}^{P}\left(\alpha_{2}\right)\right) d Y_{2}-\left[\int_{0}^{K\left(\underline{\theta}, D_{2}^{P}\left(\alpha_{2}\right)\right)} Y_{2} f_{2}\left(Y_{2} \mid \underline{\theta}, D_{2}^{P}\left(\alpha_{2}\right)\right) d Y_{2}-D_{2}^{P}\left(\alpha_{2}\right)\right]\right\}$.

Hence, from (33) and (34), $U_{1}^{S}\left(\alpha_{2}\right) \geq U_{1}^{P}\left(\alpha_{2}\right)$ if:

$$
\begin{array}{r}
\int_{D_{2}^{P}\left(\alpha_{2}\right)}^{K\left(\underline{\theta}, D_{2}^{P}\left(\alpha_{2}\right)\right)}\left(Y_{2}-D_{2}^{P}\left(\alpha_{2}\right)\right) f_{2}\left(Y_{2} \mid \underline{\theta}, D_{2}^{P}\left(\alpha_{2}\right)\right) d Y_{2}-\left[\int_{0}^{K\left(\underline{\theta}, D_{2}^{P}\left(\alpha_{2}\right)\right)} Y_{2} f_{2}\left(Y_{2} \mid \underline{\theta}, D_{2}^{P}\left(\alpha_{2}\right)\right) d Y_{2}-D_{2}^{P}\left(\alpha_{2}\right)\right] \geq \\
\int_{D_{2}^{B}}^{K\left(\underline{\theta}, D_{2}^{B}\right)}\left(Y_{2}-D_{2}^{B}\right) f_{2}\left(Y_{2} \mid \underline{\theta}, D_{2}^{B}\right) d Y_{2}-\left[\int_{0}^{K\left(\underline{\theta}_{2}^{*} \underline{D}_{2}^{*}\right)} Y_{2} f_{2}\left(Y_{2} \mid \underline{\theta}, \underline{D}_{2}^{*}\right) d Y_{2}-\underline{D}_{2}^{*}\right] .
\end{array}
$$

Notice that:

$$
\int_{D_{2}^{B}}^{K\left(\underline{\theta}, D_{2}^{B}\right)}\left(Y_{2}-D_{2}^{B}\right) f_{2}\left(Y_{2} \mid \underline{\theta}, D_{2}^{B}\right) d Y_{2} \geq \int_{D_{2}^{P}\left(\alpha_{2}\right)}^{K\left(\underline{\theta}, D_{2}^{P}\left(\alpha_{2}\right)\right)}\left(Y_{2}-D_{2}^{P}\left(\alpha_{2}\right)\right) f_{2}\left(Y_{2} \mid \underline{\theta}, D_{2}^{P}\left(\alpha_{2}\right)\right) d Y_{2}
$$


by definition of $D_{2}^{B}$, where the equality holds for $\alpha_{2}=\tilde{\alpha}_{2}$. Also:

$$
\int_{0}^{K\left(\underline{\theta}, \underline{D}_{2}^{*}\right)} Y_{2} f_{2}\left(Y_{2} \mid \underline{\theta}, \underline{D}_{2}^{*}\right) d Y_{2}-\underline{D}_{2}^{*} \geq \int_{0}^{K\left(\underline{\theta}, D_{2}^{P}\left(\alpha_{2}\right)\right)} Y_{2} f_{2}\left(Y_{2} \mid \underline{\theta}, D_{2}^{P}\left(\alpha_{2}\right)\right) d Y_{2}-D_{2}^{P}\left(\alpha_{2}\right),
$$

by definition of $\underline{D}_{2}^{*}$, where the equality holds for $\alpha_{2}=0$.

Hence, from (33)-(34) and (36)-(37), we have that $U_{1}^{P}(0)>U_{1}^{S}(0)$ and $U_{1}^{S}\left(\tilde{\alpha}_{2}\right)>U_{1}^{P}\left(\tilde{\alpha}_{2}\right)$. Also, the RHS in (35) is independent of $\alpha_{2}$. Because (i) the first term of the left-hand-side (LHS) in (35) is increasing in $\alpha_{2}$ and (ii) the second term of the left-hand-side (LHS) in (35) is decreasing in $\alpha_{2}$, the LHS in (35) is increasing in $\alpha_{2}$. This finally establishes that there exists a unique threshold $\alpha_{2}^{*} \in\left(0, \tilde{\alpha}_{2}\right)$ such that the separating mechanism Pareto dominates the pooling rule for $\alpha_{2} \geq \alpha_{2}^{*}$.

As $\alpha_{2}$ increases, on the one hand, the expected cost to $S_{1}$ of the separating mechanism decreases, because the probability of $S_{2}$ being the recipient of the transfer is smaller; on the other hand, the expected cost to $S_{1}$ of bail-out under the pooling equilibrium (i) increases because of the higher deficit-ceiling $\left(D_{2}^{P}\right)$ and (ii) decreases because of the lower probability that bail-out occurs. However, by construction, $S_{1}$ strictly prefers allocationg the 'low potential output-type' of $S_{2}$ the transfer $\underline{t}_{2}^{*}$ rather than incurring the expected cost of bail-out when $D_{2}(\underline{\theta})=D_{2}^{B}$ : as $\alpha_{2}$ increases, because of $(i)$, the separating mechanism becomes less costly to $S_{1}$ than the pooling mechanism and, as a consequence, becomes Pareto dominant.

Figure 4 plots $S_{1}$ 's utility from the (i) decentralized, (ii) pooling, and (iii) separating solutions. Figure 5 plots the utilities the $\underline{\theta}$-type (Figure 5a) and the $\bar{\theta}$-type (Figure $5 \mathrm{~b}$ ) of $S_{2}$ obtain from the three alternative solutions.

In Figure $4, S_{1}$ 's utility from the separating mechanism $\left(U_{1}^{S}\right)$ is higher than its utility from the decentralized solution $\left(U_{1}^{B}\right), \forall \alpha_{2} \in[0,1]$ (see Proposition 2); also, for $\alpha_{2}<\tilde{\alpha}_{2}, S_{1}$ 's utility from the pooling mechanism $\left(U_{1}^{P}\right)$ is higher than its utility from the decentralized mechanism, while the two utilities are the same for $\alpha_{2} \geq \tilde{\alpha}_{2}$ (see the proof of Proposition 3). In Figure 5a, the bold horizontal line represents $S_{2}$ 's utility from both the separating and the decentralized mechanism when $S_{2}$ is characterized by a low potential output (i.e., $U_{2}^{S}(\underline{\theta})=U_{2}^{B}(\underline{\theta})$ ); $S_{2}$ obtains a strictly lower utility from the pooling mechanism - with respect to the alternative solutions - for $\alpha_{2}<\tilde{\alpha}_{2}$, while $S_{2}$ 's utility is independent of the solution adopted for $\alpha_{2} \geq \tilde{\alpha}_{2}$. Finally, in Figure 5b, the bold horizontal line represents $S_{2}$ 's utility from both the separating and the decentralized mechanism when $S_{2}$ is characterized by a high potential output (i.e., $U_{2}^{S}(\bar{\theta})=U_{2}^{B}(\bar{\theta})$ ); $S_{2}$ obtains a strictly lower utility from the pooling mechanism - with respect to the alternative solutions $-\forall \alpha_{2} \in[0,1]$. Figure 4 and Figure 5 graphically show that the separating mechanism Pareto dominates both the pooling 
Figure 4: Country 1's Utility under the (i) Decentralized, (ii) Pooling, and (iii) Separating Solutions.

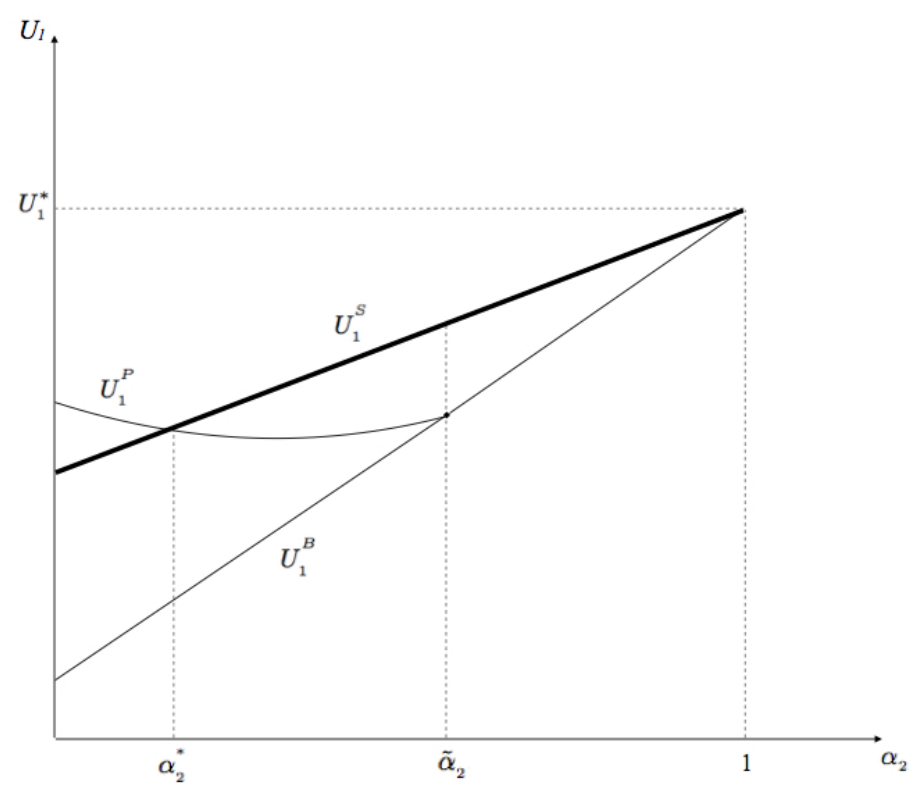

Figure 5: Country 2's Utility under the (i) Decentralized, (ii) Pooling, and (iii) Separating Solutions.

(a) Low Potential Output.

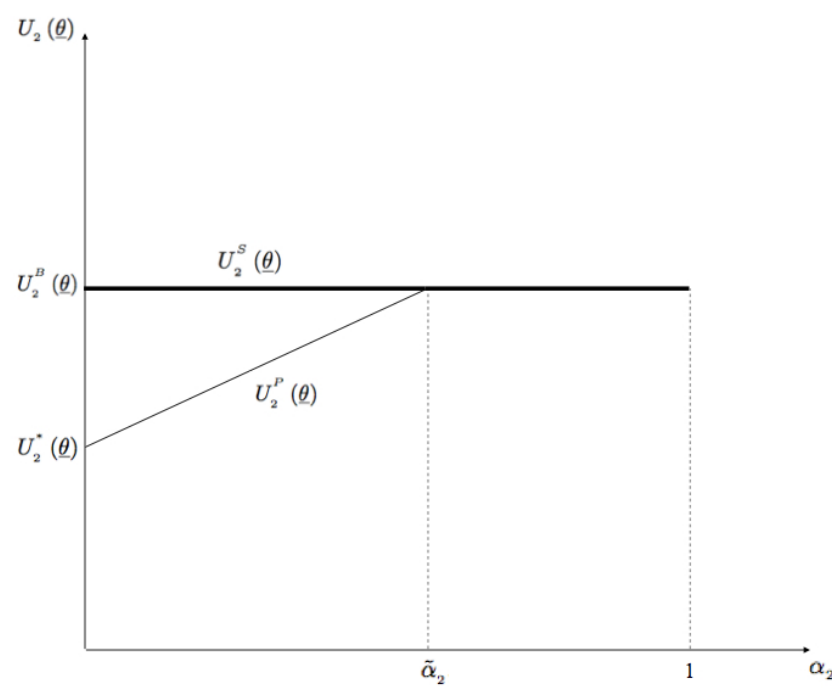

(b) High Potential Output.

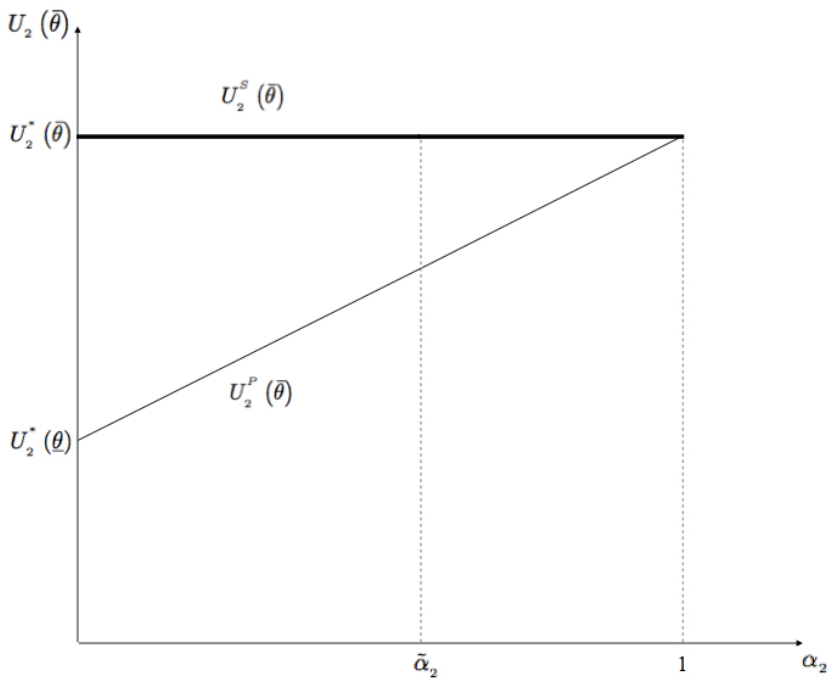


and the decentralized solutions for $\alpha_{2} \geq \alpha_{2}^{*}$.

To sum up, in the presence of asymmetric information and bail-out, as the prior probability that $S_{2}$ 's type has a high potential output increases, it pays off to all $M U$ 's member states to design a mechanism that make each type of $S_{2}$ self-select in its efficient level of borrowing. In fact, both types of $S_{2}$ gain from this mechanism: when characterized by a low potential output, $S_{2}$ does not overborrow on the financial market and receives a positive trasfer from the union; when characterized by a large potential output, $S_{2}$ has access to its efficient level of borrowing. $S_{1}$ also gains from the separating mechanism, as it avoids the increasing expected cost of bailing $S_{2}$ out when characterized by a low potential output, in exchange of the payment of a fixed transfer to $S_{2}$ (when characterized by a low potential output).

\section{A Comparison with EMU's Current Fiscal Framework}

As discussed in Section 2, the fiscal framework currently implemented within the European Monetary Union $(E M U)$ encompasses a 'cyclically-adjusted' cap on member states' borrowing level. More specifically, from (1), the target imposed on each member state regarding the nominal deficit-to-GDP ratio is adjusted - i.e., relaxed - were the member state to experience a negative output gap. Obviously, the size of the borrowing constraint's relaxation depends on the member state's potential output. Because Excessive Deficit Procedures are iniziated only in case a member state overborrows with respect to its cyclically-adjusted cap, each member state has an incentive to misrepresent (upward) its potential output so as to run a higher nominal deficit.

Depending on whether we believe that member states are able to affect EMU's final estimates of their own potential outptut, the current EMU's fiscal framework is captured in two different ways. If one believes that EMU (possibly partially) bases its fiscal policy on the member state's estimates of their own potential output, the European fiscal policy is similar to one in which $E M U$ offers to a member state the possibility to choose between two cyclically-adjusted deficit-to-GDP thresholds - i.e., $D^{*}(\underline{\theta})$ and $D^{*}(\bar{\theta})$ - where none of the two borrowing upperbounds are subject to a fine (i.e., $t(\theta)=0$, for $\theta \in\{\underline{\theta}, \bar{\theta}\}$ ). As shown in the previous section, because of bail-out, if member states are given the possibility to choose between these two borrowing thesholds, they prefer to run a high deficit-to-GDP ratio irrespective of their cyclical position. If one believes that $E M U$ only makes use of its own estimates $(\alpha \in[0,1])$ of a member state's potential output instead, the current European fiscal policy corresponds to one in which $M U$ sets a single pooling borrowing threshold $D^{P}(\alpha)$. In that sense, point $D^{P}(\alpha)$ is the (country-specific) MTO currently set by $E M U$ : in this second case also, overborrowing occurs when a member state is characterized by a low potential output (i.e., when $\theta=\underline{\theta})$. 
To rephrase it, in the presence of asymmetric information and bail-out, the attempt to implement a more efficient policy may well degenerate into an inefficient overborrowing at the Union level. In light of the explanation we put forward in this paper, it is not surprising, then, we observe many member states running excessive deficits and, therefore, postponing the achievement of their Medium Term Objective (European Central Bank [2015]).

Provided EMU aims at implementing a cyclically-adjusted mechanism while eliciting member states' private information, the mechanism proposed in this paper presents one major difference with respect to the current European fiscal framework: to avoid overborrowing when a member state is not far from its potential, the low deficit required from a member state characterized by a low potential output must come with an ex-post transfer to be received from the other members of the Union. Possibly, it can be a transfer specifically aimed at raising its potential output. Under this light, the mechanism we propose can be seen as a device to reduce national borrowing (which may or may not be aimed at permanently raise the potential output level) and increase expenditure. This mechanism has two crucial features: (i) it comes from the "federal" level, therefore it implies a degree of fiscal risk sharing within the Union, and (ii) it can be specifically targeted towards goals (possibly jointly determined between the nation state and the monetary union) regarding a permanent increase of a member state's production possibilities, because these states are the optimal recipients of the transfers.

\section{Concluding Remarks}

The model presented in this paper captures the main features of a fiscal framework within a monetary union in the presence of (i) asymmetric information over member states' fundamentals - i.e., potential output and, therefore, output gap - and (ii) bail-out among member states when shocks jeopardize the ability of some members to pay back their debt. In such an environment, optimal counter-cyclical fiscal policies are not incentive-compatible because bail-out (a) incentivizes member states to misreprent their current output gap and overborrow on the financial market. Furthermore, bail-out lowers lenders' (member states') incentives to discriminate among borrowers' (signal their) cyclical position.

Unlike single member states, the monetary union internalizes the externalites and distortions created by the interplay between asymmetric information and bail-out and designs a mechanism to discriminates borrowers based on the magnitude of their potential output. Such a mechanism implies the payment by the monetary union of a lump-sum transfer to the member state characterized by a lower (negative) output gap - and, therefore, a smaller magnitude of the government spending multiplier - so that each member 
state can self-select into its efficient level of borrowing. The efficiency gains generated by this separating mechanism makes it Pareto dominant with respect to a decentralized equilibrium in which member states are unconstrained in their borrowing choice. Mostly, provided there is a sufficiently high prior probability that the member state is characterized by a high potential output, the separating mechanism Pareto dominates a pooling rule in which the monetary union sets a unique borrowing constraint. Because the pooling rule is probably the best approximation of the current cyclically-adjusted rule under the Fiscal Compact Treaty, our results has important policy implications.

The fiscal framework currently implemented within the European Monetary Union induces inefficient overborrowing by member states. Many observers note that the future of the European Union's economic and political integration relies on its ability to deeply reform this framework, as it has been made evident by the 2012 bail-out of Greece. Our opinion is that there are thee alternative options ahead of this process: (i) member states manage to work out an unambigous and perfectly observable measure of potential output, so to eradicate the asymmetric information problem, (ii) the European Union acknowledges the existence of an asymmetric information problem that makes the implementation of fiscal rules based on potential output too complicated and, therefore, goes back to solely nominal targets, or (iii) the European Union acknowledges the existence of an asymmetric information problem and reforms its fiscal framework to tackle it. The mechanism proposed in this paper is an attempt to explore the theoretical implications of this last option. 


\section{References}

- Alesina, A., Tabellini, G. (1990). A Positive Theory of Fiscal Deficits and Government Debt. Review of Economic Studies, 57, 403-414.

- Andrle, M. (2015). Reforming Fiscal Governance in the European Union. IMF Staff Discussion Note. SDN $15 / 09$.

- Artis, M.J., Buti, M., (200). Close to Balance or in Surplus. A Policy-Maker's Guide to the Implementation of the Stability and Growth Pact. Journal of Common Market Studies 38, 563-592.

- Andres, J., Domènech,R., (2006). Automatic Stabilizers, Fiscal Rules and Macroeconomic Stability. European Economic Review 50, 1487-1506.

- Auerbach, A.J., and Y. Gorodnichenko (2012a), Measuring the Output Responses to Fiscal Policy, American Economic Journal: Economic Policy, 4, 1-27.

- Auerbach, A.J., and Y. Gorodnichenko (2012b), "Fiscal Multipliers in Recession and Expansion" in "Fiscal Policy after the Financial Crisis", A. Alesina and F.Giavazzi (eds), University of Chicago Press.

- Batini, N., Callegari, G. And G.Melina (2012), "Successful Austerity in the United States, Europe and Japan", IMF Working Paper 12/190.

- Baum, A., Poplawski-Ribeiro, M. and A.Weber (2012), "Fiscal Multipliers and the State of the Economy", IMF Working Paper 12/286

- Beetsma, R., Bovenberg, A. (1999). Does Monetary Unification Lead to Excessive Debt Accumulation? Journal of Public Economics 74, 299-325.

- Beetsma, R., Uhlig, H. (1999). An Analysis of the Stability and Growth Pact. Economic Journal 109, $546-71$.

- Besfamille, M. (2003). Local Public Works and Intergovernmental Transfers under Asymmetric Information. Journal of Public Economics 88, 353-375.

- Blanchard, O.J. (1990). Suggestions for a New Set of Fiscal Indicators" OECD Economics Department Working Papers No.79, OECD Publishing. 
- Bolton, P., Jeanne, O. (2011). Sovereign Default Risk and Bank Fragility in Financially Integrated Economies. IMF Economic Review Vol.59, No.2.

- Bordignon, M., Manasse, P., Tabellini, G. (2001). Optimal Regional Redistribution Under Asymmetric Information. American Economic Review 91, 709-723.

- Bottazzi, L., Manasse, P. (2005). Information and Monetary Policy in Common Currency Areas. Journal of Money, Credit and Banking 37, 603-621.

- Brunila, A. (2002). Fiscal Policy: Coordination, Discipline and Stabilization. Helsinki: Bank of Finland.

- Buiter, W., Corsetti, G., Roubini, N. (1993). Excessive Deficits: Sense and Non-Sense in the Treaty of Maastricht. Economic Policy 8, 57-100.

- Buti, M., Eijffinger, S., Franco, D. (2002). Revisiting the Stability and Growth Pact: Grand Design or Internal Adjustment? EU Commission, Center for Economic Research and Banca d'Italia.

- Bruck, T., Zwiener, R., (2006). Fiscal Policy Rules for Stabilisation and Growth: A Simulation Analysis of Deficit and Expenditure Targets in a Monetary Union. Journal of Policy Modeling 28, 357-369.

- Cacciotti, M, Caretta,A., De Castro, A. Masi, E., Morea, R. (2014). Metodologie per il calcolo del prodotto potenziale e delle regole del debito e della spesa, previste dal nuovo sistema di governance europea. Italian Ministry of Economy and Finance, Treasury Department, January 28, 2014.

- Canzoneri, M. B., Diba, B.T., (2001). The Stability and Growth Pact: A Delicate Balance or an Albatross? in Brunila, A., Buti, M., Franco, D. (eds) - The Stability and Growth Pact: The Fiscal Architecture of EMU. Basingstoke: Palgrave.

- Carnot, N. (2014). Evaluating Fiscal Policy: A Rule of Thumb. European Economy Economic Papers 526, European Commission, Brussels.

- Christiano, L., Eichenbaum and M, Rebelo, S. (2009), When is the Government Spending Multiplier Large?, Journal of Political Economy 119, 78-121.

- Chari, V.V., Kehoe, P., J., (2007). On the Need for Fiscal Constraints in a Monetary Union. Journal of Monetary Economics 54, 2399-2408.

- Cooper, R., Kempf, H., (2000). "Designing Stabilization Policy in a Monetary Union". NBER Working Paper No.7607. 
- Corders, T., Kinda, T., Muthoora, P., Weber, A. (2015). Expenditure Rules: Effective Tools for Sound Fiscal Policy. IMF Working Paper 15/29.

- Cornes R.C., Silva, E.C.D., (2002). Local Public Goods, Inter-regional Transfers and Private Information. European Economic Review 46, 329-356.

- Corsetti, G., Guimaraes, B., Roubini, N. (2006). International Lending of Last Resort and Moral Hazard: A Model of IMF's Catalytic Finance. Journal of Monetary Economics 53, 441-471.

- Cottarelli, C. (2015). Potential Growth rates and the Working of SGP Fiscal Rules". Vox- CEPR's Policy Portal.

- Cukierman,A., Edwards, S., Tabellini, G. (1992). Seignorage and Political Instability . American Economic Review 82, 537-555.

- Debrun, X., Epstein, N., Symansky, S. (2008). A New Fiscal Rules: Should Israel Go Swiss?". IMF Working Paper 08/87, IMF, Washington.

- Denis, C., Morrow, Mc., Roger, W. (2002). Production Function Approach to Calculating Potential Growth and Output Gaps. Estimates for the EU Member States and the US. Economic Papers 176, European Commission.

- Dixit, A. (2001). Games of Monetary and Fiscal Interactions in the EMU. European Economic Review $45,589-613$.

- Dixit, A., Lambertini, L., (2001). Monetary -Fiscal Policy Interactions and Commitment Versus Discretion in a Monetary Union. European Economic Review 45, 977-987.

- Engwerda, J. C., van Aarle B., Plasmans, J., (2002). Cooperative and non-cooperative Fiscal Stabilization Policies in the EMU. Journal of Economic Dynamics and Control 26, 451-481.

- European Commission - Directorate General for Economic and Financial Affairs, (2013), "Vade mecum on the Stability and Growth Pact" Occasional Papers 151.

- European Commission (2015), "Commission issues guidance to encourage structural reforms and investment" - Strasbourg, 13 January 2015.

- Ferrè, M. (2008). Fiscal Policy Coordination in the EMU. Journal of Policy Modelling 30, 221-235.

- Hall,R. (2009. By How Much Does GDP Rise if the Government Buys More Output? Brookings Papers on Economic Activity, 2, pp.183-231 
- Harding, D., and A.Pagan (2002), "Dissecting the Cycle: a Methodological Investigation". Journal of Monetary Economics 49, 365-81.

- Innes, R. (1991). Investment and Government Intervention in Credit Markets when there is Asymmetric Information. Journal of Public Economics 46, pp. 347-381.

- Keynes, J.M. (1936). The General Theory of Employment, Interest and Money. New York: MacMillan - Kinda, T. (2015). "Anchoring Sustainable Fiscal Policy: A New Fiscal Rules in Canada". Selected Issues Paper, IMF Country Report 15/23.

- Lane, P. (2012). The European Sovereign Debt Crisi. Journal of Economic Perspectives 26, 49-68.

- Larch, M., Turrini, A. (2009). The Cyclically-Adjusted Budget Balance in EU Fiscal Policy Making: A Love at First Sight Turned into a Mature Relationship. European Economy, Economic Papers 374.

- Lockwood, B. (1999). Inter-regional Insurance. Journal of Public Economics 72, 1-37.

- Manasse, P. (2007). "Deficit Limits and Fiscal Rules for Dummies". IMF Staff Papers 54, 3.

- Marcellino, M., Musso, A. (2011). The Reliability of Real-Time Estimates of the Euro-Area Output Gap. Economic Modelling 28, 1842-56.

- Masten, I., Gnip, A.G. (2016). Stress Testing the EU Fiscal Framework. Journal of Financial Stability - forthcoming

- Mourre, G., Isbasoiu, G.M., Paternoster, D., Salto, M. (2013). The Cyclically-Adjusted Budget Balance Used in the EU Fiscal Framework: an Update. European Economy- Economic Papers 47.

- Oates, W.E. (2005). Toward a Second-Generation Theory of Fiscal Federalism. International Tax and Public Finance 12, 349-373.

- Petrova, I. (2012). "Iceland's Policy Objectives Under a New Fiscal Rule". Selected Issues Paper, IMF Country Report 12/90, IMF Washington.

- Roeger, W. (2006). The Production Function Approach to Calculating Potential Growth and Output Gaps. Estimates for the EU Member States and the US.

- Roubini,N., Sachs, J., (1989). Political and Economic Determinants of Budget Deficits in the Industrial Democracies. European Economic Review 33, 903-938. 
- Stockman, D.R.,(2001). Balanced-Budget Rules: Welfare Loss and Optimal Policies. Review of Economic Dynamics 4, 438-459.

- Siu, H.E. (2004). Optimal Fiscal and Monetary Policy with Sticky Prices. Journal of Monetary Economics 51, 575-607.

- Tabellini,G., Alesina,.A. (1990). Voting on the Budget Deficit. American Economic Review 80, 37-49.

- Tereanu, E., Tuladhar A., Simone, A. (2014) Structural Balance Targeting and Output Gap Uncertainty. IMF Working Paper, WP/14/107.

- Tirole, Jean (2006), The Theory of Corporate Finance, Princeton University Press.

- Von Hagen, J., Eichengreen, B. Federalism, Fiscal Restraints and European Monetary Union. American Economic Review 86, 134-138.

- Woodford, M. (2010), "Simple Analytics of the Government Expenditure Multiplier", American Economic Journal: Macroeconomics 3, 1-35.

- Wyplosz, C. (2002). Fiscal Discipline in EMU: Rules or Institutions? Geneva: Graduate Institute for International Studies. 


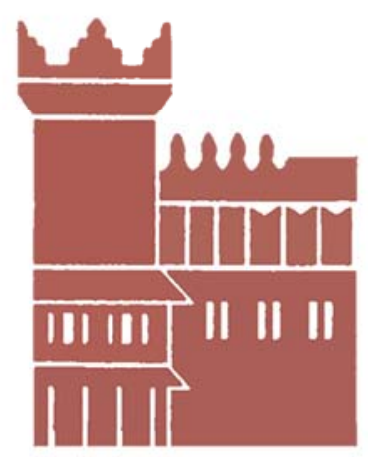

Alma Mater Studiorum - Università di Bologna DEPARTMENT OF ECONOMICS

Strada Maggiore 45

40125 Bologna - Italy

Tel. +39051 2092604

Fax +390512092664

http://www.dse.unibo.it 